\title{
Wilderness recreation---an analysis of social carrying capacity, regional differences, and the role of gender
}

\author{
Katharina Will
}

Follow this and additional works at: https://researchrepository.wvu.edu/etd

\section{Recommended Citation}

Will, Katharina, "Wilderness recreation---an analysis of social carrying capacity, regional differences, and the role of gender" (2016). Graduate Theses, Dissertations, and Problem Reports. 6953.

https://researchrepository.wvu.edu/etd/6953

This Thesis is protected by copyright and/or related rights. It has been brought to you by the The Research Repository @ WVU with permission from the rights-holder(s). You are free to use this Thesis in any way that is permitted by the copyright and related rights legislation that applies to your use. For other uses you must obtain permission from the rights-holder(s) directly, unless additional rights are indicated by a Creative Commons license in the record and/ or on the work itself. This Thesis has been accepted for inclusion in WVU Graduate Theses, Dissertations, and Problem Reports collection by an authorized administrator of The Research Repository @ WVU. For more information, please contact researchrepository@mail.wvu.edu. 
Wilderness Recreation

An Analysis of Social Carrying Capacity, Regional Differences, and the Role of Gender

\author{
Katharina Will
}

Thesis submitted to the

Davis College of Agriculture, Forestry and Consumer Sciences

at West Virginia University

in partial fulfillment of the requirements for the degree of

Master of Science in

Recreation, Parks, and Tourism Resources

\author{
Robert C. Burns, Ph.D., Chair \\ Chad D. Pierskalla, Ph.D. \\ David Smaldone, Ph.D.
}

Division of Forestry and Natural Resources

Morgantown, West Virginia

2016

Keywords: Outdoor Recreation, Social Carrying Capacity, Motivations, Gender, Regional Differences.

Copyright 2016 Katharina Will 


\begin{abstract}
Wilderness Recreation

An Analysis of Social Carrying Capacity, Regional Differences, and the Role of Gender.
\end{abstract}

\author{
Katharina Will
}

The overall purpose of this thesis was to identify gender-based and regional differences in wilderness recreation. First, demographic information, trip characteristics, motivation satisfaction, crowding and conflict variables were analyzed across all wilderness areas. Then, regional differences and gender-based differences were examined.

On-site surveys were conducted in eight wilderness areas in the Klamath National Forest and the Stanislaus National Forest in California, as well as in the Deschutes and Willamette National Forests in Oregon. Data collection took place in summer and early fall of 2010 and resulted in a total of 2,559 usable surveys. Frequencies and valid percentages were used to describe characteristics of the entire sample. Independent samples t- tests, One Way Analysis of Variance (ANOVA), and Pearson's Chi square test were utilized to analyze differences between the three regions and between female and male visitors.

The majority of the sample was male. Education and income levels tended to be high and there was a wide age range. Very few respondents said they were Hispanic or Latino and most respondents identified as white. The sample was evenly split between day users and overnight users. The most popular primary activities were hiking and walking, backpacking, camping, and viewing natural features. Satisfaction levels were high, while crowding and conflict levels were low. Motivational items relating to the physical setting and catharsis items were most important for respondents.

The comparison between wilderness areas in the three different regions revealed that similar overall patterns hold true for each of the individual regions. Generally, satisfaction levels were high, crowding and conflict were not an issues, and physical settings and catharsis items played the most important role regarding motivations. However, compared to the other portions of the sample visitors in the Stanislaus National Forest seem somewhat different with regards to motivations and satisfaction levels.

The analysis of gender based differences across all wilderness areas revealed several significant results with regards to motivations and trip characteristics. Still, none of the overall significant variables were also significant for all three of the individual regions. Nevertheless, there were some trends that were apparent in each region: Women were more likely to be day users, they spent less time recreating in wilderness, and they often place higher importance on motivational items than their male counterparts. There was an unusually high proportion of female visitors in the Deschutes and Willamette National Forests. Also, a larger amount of variables produced significant results for the comparison between males and females in this region. Findings from this study suggest that gender-based differences vary from one area to another and therefore should always be discussed in a regional context.

Last, this thesis discusses suggestions for future research projects and management implications. 


\section{ACKNOWLEDGEMENTS}

I would like to thank my committee members Dr. Dave Smaldone and Dr. Chad Pierskalla not just for their advice on this thesis, but also for their constant support throughout the past two years. Also, I would like to express my gratitude to my advisor Dr. Robert Burns for giving me the opportunity to pursue a Master's degree at West Virginia University and for enabling me to gain valuable experiences in the beautiful Pacific Northwest for four summers.

Thank you to Lidiane \& Micah Gregory, Jonas Levêque, Ashley Popham, Emma Laferre, and Teri Chuprinko. You are the best office mates, fellow grad students, and friends anyone could wish for.

I am incredibly lucky to have the most wonderful and supportive family. Danke and thank you all for everything! 


\section{TABLE OF CONTENTS}

ABSTRACT

ACKNOWLEDGEMENTS iii

TABLE OF CONTENTS

LIST OF TABLES vi vi

LIST OF FIGURES viii

CHAPTER 1- INTRODUCTION 1

Purpose of the Study 2

Research Questions 3

Delimitations and Limitations 3

Definition of Terms $\quad 4$

CHAPTER 2 - LITERATURE REVIEW 6

Wilderness Recreation and Management $\quad 6$

Comparative Wilderness Recreation Studies $\quad 8$

$\begin{array}{ll}\text { Social Carrying Capacity } & 9\end{array}$

Measuring Social Carrying Capacity in Wilderness: Visitor Satisfaction, Crowding, and $\begin{array}{ll}\text { Conflict } & 10\end{array}$

Motivations $\quad 12$

The Role of Gender in Wilderness Recreation 13

CHAPTER 3 - METHODOLOGY 17

$\begin{array}{ll}\text { Study Areas } & 17\end{array}$

Survey Instrument 19

Data Collection $\quad 21$

Testing of the Research Questions $\quad 22$

CHAPTER 4 - RESULTS 25

RQ1: What does the sample of visitors look like across the wilderness areas? 25

RQ2: What motivates visitors to recreate in the wilderness areas? 29

RQ3: What is the satisfaction level of respondents across the wilderness areas? 31

RQ4: What are the levels of crowding and conflict across the wilderness areas? 33

RQ5: Are there significant differences in visitors' motivations, satisfaction, and perceived crowding levels between the wilderness areas in the Deschutes-Willamette, Klamath, and Stanislaus National Forests?

RQ 6: Are there significant differences in trip characteristics, motivations, satisfaction, crowding and conflict between female and male visitors? 
RQ 6a: Can a typology be derived from variables such as motivations, satisfaction levels, perceived crowding and trip type for female and male visitors?

RQ1: What does the sample of visitors look like across the wilderness areas? 57

RQ2: What motivates visitors to recreate in the wilderness areas? 59

RQ3: What is the satisfaction level of respondents across the wilderness areas? 60

RQ4: What are the levels of crowding and conflict across the wilderness areas? 60

RQ5: Are there significant differences in visitors' motivations, satisfaction, and perceived crowding levels between the wilderness areas in the Deschutes-Willamette, Klamath, and Stanislaus National Forests?

RQ6: Are there significant differences in trip characteristics, motivations, satisfaction, crowding and conflict between female and male visitors?

RQ6a: Can a typology be derived from variables such as motivations, satisfaction levels, perceived crowding and trip characteristics for female and male visitors?

Management Implications

$\begin{array}{ll}\text { Recommendations for Future Research } & 74\end{array}$

$\begin{array}{ll}\text { Conclusions } & 76\end{array}$

$\begin{array}{ll}\text { REFERENCES } & 78\end{array}$

APPENDIX A: SURVEY INSTRUMENT $\quad 84$ 


\section{LIST OF TABLES}

\begin{tabular}{|c|c|c|}
\hline Table & Title & Page \\
\hline 1 & Study Area and Number of Surveys & 22 \\
\hline 2 & Sociodemographic Profile of Respondents & 26 \\
\hline 3 & Sociodemographic Profile of Respondents Continued & 27 \\
\hline 4 & Overnight and Day Use & 27 \\
\hline 5 & Trip Length and Group Characteristics & 28 \\
\hline 6 & Group Size & 28 \\
\hline 7 & Primary Activity & 29 \\
\hline 8 & Motivations & 30 \\
\hline 9 & Primary Reason to Visit & 31 \\
\hline 10 & Overall Satisfaction & 31 \\
\hline 11 & Satisfaction with Quality Attributes & 32 \\
\hline 12 & Level of Agreement with Trip Attributes & 33 \\
\hline 13 & Expected and Perceived Crowding & 34 \\
\hline 14 & Actual and Preferred Crowding & 34 \\
\hline 15 & Level of Agreement with Crowding and Conflict Attributes & 36 \\
\hline 16 & Preferred Group Size & 36 \\
\hline 17 & Social Conflict & 37 \\
\hline 18 & Results of Comparison of Means of Motivations for the Three Regions & 39 \\
\hline 19 & $\begin{array}{l}\text { Results of Comparison of Means of Overall Satisfaction, Satisfaction with } \\
\text { Quality Attributes, and Level of Agreement with Trip Attributes for the } \\
\text { Three Regions }\end{array}$ & 41 \\
\hline 20 & $\begin{array}{l}\text { Results of Comparison of Means of Perceived Crowding for the Three } \\
\text { Regions }\end{array}$ & 41 \\
\hline 21 & $\begin{array}{l}\text { Results of Cross Tabulations for Overnight and Day Use for Female and } \\
\text { Male Visitors }\end{array}$ & 42 \\
\hline 22 & $\begin{array}{l}\text { Results of Comparison of Means of Trip Length and Group Characteristics } \\
\text { for Female and Male Visitors }\end{array}$ & 42 \\
\hline 23 & $\begin{array}{l}\text { Results of Comparison of Means of Motivations for Male and Female } \\
\text { Visitors }\end{array}$ & 44 \\
\hline 24 & $\begin{array}{l}\text { Results of Comparison of Cross Tabulations for Primary Reason to Visit for } \\
\text { Female and Male Visitors }\end{array}$ & 44 \\
\hline 25 & $\begin{array}{l}\text { Results of Comparison of Means of Overall Satisfaction, Satisfaction with } \\
\text { Quality Attributes, and Level of Agreement with Trip Attributes for Female } \\
\text { and Male Visitors }\end{array}$ & 45 \\
\hline 26 & $\begin{array}{l}\text { Results of Cross Tabulation for Expected and Perceived Crowding for } \\
\text { Female and Male Visitors }\end{array}$ & 46 \\
\hline 27 & $\begin{array}{l}\text { Results of Comparison of Means of Actual and Preferred Crowding for } \\
\text { Female and Male Visitors }\end{array}$ & 47 \\
\hline 28 & $\begin{array}{l}\text { Results of Comparison of Means of Level of Agreement with Crowding and } \\
\text { Conflict Attributes for Male and Female Visitors }\end{array}$ & 48 \\
\hline 29 & $\begin{array}{l}\text { Results for Cross Tabulations for Preferred Group Size for Female and } \\
\text { Male Visitors }\end{array}$ & 49 \\
\hline 30 & $\begin{array}{l}\text { Results of Cross Tabulation for Social Conflict for Female and Male } \\
\text { Visitors }\end{array}$ & 49 \\
\hline 31 & Proportions Female and Male Visitors per Region & 50 \\
\hline
\end{tabular}




\begin{tabular}{|c|l|c|}
\hline 32 & $\begin{array}{l}\text { Results of Comparison of Means of Motivations for Female and Male } \\
\text { Visitors in the Deschutes and Willamette National Forests }\end{array}$ & 51 \\
\hline 33 & $\begin{array}{l}\text { Results of Comparison of Means of Motivations for Female and Male } \\
\text { Visitors in the Stanislaus National Forest }\end{array}$ & 52 \\
\hline 34 & $\begin{array}{l}\text { Results of Comparison of Means of Motivations for Female and Male } \\
\text { Visitors in the Klamath National Forest }\end{array}$ & 53 \\
\hline 35 & $\begin{array}{l}\text { Results of Comparison of Means of Selected Variables for Female and } \\
\text { Male Visitors in the Deschutes and Willamette National Forests }\end{array}$ & 54 \\
\hline 36 & $\begin{array}{l}\text { Results of Comparison of Means of Selected Variables for Female and } \\
\text { Male Visitors in the Stanislaus National Forests }\end{array}$ & $\begin{array}{l}\text { Results of Comparison of Means of Selected Variables for Female and } \\
\text { Male Visitors in the Klamath National Forests }\end{array}$ \\
\hline
\end{tabular}




\section{LIST OF FIGURES}

\begin{tabular}{|c|l|c|}
\hline Figure & Title & Page \\
\hline 1 & Klamath and Stanislaus National Forests, CA & 17 \\
\hline 2 & Deschutes and Willamette National Forests, OR & 17 \\
\hline
\end{tabular}




\section{CHAPTER 1- INTRODUCTION}

“... for the permanent good of the whole people." - Wilderness Act of 1964

Federally designated wilderness areas in US National Forests have been a popular setting for outdoor recreation for decades. Because of increased visitation to these protected areas visitor monitoring is important to help public land managers to make well informed decisions in order to provide opportunities for high quality recreation experiences.

As the number of visitors to public lands significantly increased in the 1960 s concerns about potential negative impacts of high recreation use on both the natural resource and the visitors' experiences arose. Since then several frameworks and concepts have been developed to measure and analyze how much recreation use of an area is too much. Examples are the limits of acceptable change model by Stankey et al. (1984) and the concept of social carrying capacity. The latter has been one of the most widely applied concepts in outdoor recreation research. It is used to determine an area's capacity by analyzing the impact of recreation use on the quality of the visitor's experience (Wagar, 1964). Such analyses are especially important for areas designated as wilderness which is the highest form of land protection in the United States. As defined in section 2c of the Wilderness Act of 1964 such areas have to provide "outstanding opportunities for solitude or a primitive and unconfined type of recreation.” Providing wilderness managers with valuable information on their visitor's characteristics, motivations, satisfaction levels, crowding and conflict issues can lead to a more effective and customized management of the area. Thus, visitor needs can be satisfied without neglecting the protection of the physical environment.

Although there have been comparative studies on wilderness recreation use, many of these were conducted decades ago. The primary focus of these studies is on the description of visitor socio-demographics, levels of satisfaction, and measures of crowding in different 
wilderness areas. Additionally, some researchers analyzed a set of variables segmenting between day users and overnight users (Lucas, 1980; Stankey, 1980). There have been studies that compare wilderness areas in different regions against each other (Lucas, 1980).

However, these types of studies are relatively rare and do not include all the wilderness areas that are studied in this thesis.

Furthermore, there are studies that investigate differences between male and female wilderness recreationists, although that investigation is not the main focus of those research projects (Roggenbuck \& Watson, 1989; Cole \& Hall, 2005). Those studies have shown that women are a minority group in wilderness recreation, but there were no attempts to analyze visitor use monitoring data in order to explain why that is. However, since the numbers of women participating in outdoor recreation have been increasing over the past decades understanding this important minority group's motivations, satisfaction levels, and trip characteristics is critical (Bialeschki \& Henderson, 1993). Generally speaking, in order for managers to make more efficient decisions with regards to their individual user group's characteristics, segmentation between user groups is a feasible approach (Donnelly, Vaske, DeRuiter, \& King, 1996). This thesis aims at gaining a deeper understanding of gender based differences in wilderness recreation than previous studies. Segmentation is utilized to examine and explain potential differences between user groups that are defined by region and gender.

\section{Purpose of the Study}

The primary purpose of this thesis is to identify gender- based differences in wilderness recreation, as well as regional differences. Findings from this thesis will not just contribute to body of literature on outdoor recreation in protected areas in general, but also broaden the existing body of literature by analyzing the role of gender in wilderness recreation in more depth than previous studies. If possible, typology for female and male 
visitors will be derived. Moreover, this study aims at adding to the collection of scholarly work investigating differences between multiple wilderness areas, which have been rare for the areas this thesis focuses on.

Findings from this study may help managers in the Klamath, Stanislaus, Deschutes, and Willamette National Forest to better understand their visitor's motivations, characteristics, and preferences as well as the areas' social carrying capacities. Results could be used for more targeted marketing purposes and for improving opportunities for high quality wilderness recreation for different user groups.

\section{Research Questions}

RQ1: What does the sample of visitors look like across the wilderness areas?

RQ2: What motivates visitors to recreate in the wilderness areas?

RQ3: What is the satisfaction level of respondents across the wilderness areas?

RQ4: What are the levels of crowding and conflict across the wilderness areas?

RQ5: Are there significant differences in visitors' motivations, satisfaction, and perceived crowding levels between the wilderness areas in the Deschutes-Willamette, Klamath, and Stanislaus National Forests?

RQ6: Are there significant differences in trip characteristics, motivations, satisfaction, crowding and conflict between female and male visitors?

RQ6a: Can a typology be derived from variables such as motivations, satisfaction levels, perceived crowding and trip characteristics for female and male visitors?

\section{Delimitations and Limitations}

This thesis is based on data from two individual studies. Sampling occurred in eight wilderness areas in Oregon and California. Therefore, findings from this study refer to a very specific sample and not the whole population of wilderness recreationists across the US. Sampling occurred in the summer and early fall of 2010. For the data collection in the 
Klamath and Stanislaus National Forests some heavy snowpack in higher elevation very likely had an impact on surveying. The survey locations were mainly high- use trailheads. Survey days at low use entrance points to the wilderness areas in these National Forests were uncommon.

The greatest potential limitation is the relative inaccuracy of some variables. Since two individual databases were merged into one for statistical analysis, some of the variables had to be adjusted.

Reporting overall satisfaction on a three point scale instead of a five or six point scale is not extraordinarily precise. However, in order to make satisfaction levels in all wilderness areas comparable for this thesis recoding the variable was the best solution. Simplifying complex scales into more comprehensive ones for data analysis is not uncommon and will be further discussed in the methodology section of this thesis. Additionally, outdoor recreation activities that did not appear on all survey instruments were recoded as other. One example for this is mining, which was only listed in one of the two survey instruments. Other variables on the list of activities had to be adjusted. For instance, camping in pre-existing sites and primitive or dispersed camping were combined into one variable camping for the national forests in northern California.

\section{Definition of Terms}

National Forest: Public land managed by the US Forest Service.

Wilderness: Area of wild land within a National Forest that is federally designated as wilderness under the Wilderness Act of 1964. Highest form of protection and formally defined as "an area where the earth and its community of life are untrammeled by man, where man himself is a visitor who does not remain" (Wilderness Act, 1964).

Outdoor Recreation: Pursue active and passive leisure activities like hiking, camping, or watching wildlife in an outdoor setting. 
Social Carrying Capacity: The maximum amount of recreation use an area can endure without deterioration of the natural resource and the visitor experience. In 1964, Wagar first introduced the concept of carrying capacity to outdoor recreation and concluded that the higher the visitation to an area is, the more likely it will have a negative impact on the visitor's recreation experience and the environment.

Perceived Crowding: Number of encounters with other groups that have a negative impact on the recreationist's experience. Perceived crowding is one means to measure social carrying capacity of an area.

Conflict: Severe disagreement/ incompatibility with another group or person's attitudes and/ or behavior. There are different types of conflict in outdoor recreation: between recreation activities (out-group), within recreation activities (in-group), between visitors and recreation managers, and between recreationists and other users.

Motivations: Psychological and physiological forces that are goal-driven and lead to a certain human behavior, e.g. participating in a particular outdoor recreation activity or recreating at a specific area.

Management objectives: Desired condition of the natural resource and outdoor recreation opportunities that should be provided in a recreation setting. Management objectives are the formal basis for management of an outdoor recreation area.

Outlier: A value outside the normal pattern of a variable's distribution. There are different ways to identify outliers, including using interquartile ranges and conducting a visual examination of the distribution. Outliers can be a problem when analyzing averages (means). Typology: Classification based on shared distinguishing characteristics within a group. 


\section{CHAPTER 2 - LITERATURE REVIEW}

The purpose of this chapter is to describe findings from research in outdoor recreation that are relevant to this thesis. The literature review is divided into six sections. First, literature on wilderness recreation and management, as well as comparative studies are discussed. Next, this chapter talks about social carrying capacity as measured by variables of satisfaction, crowding, and conflict, before moving on to studies on visitor's motivations to participate in outdoor recreation. Last, previous research on the role of gender in wilderness recreation is reviewed.

\section{Wilderness Recreation and Management}

The Wilderness Act of 1964 sets the legal foundation for the creation of the National Wilderness Preservation System in National Forests, National Parks, and other public lands in the United States. This act aims to protect wild lands for all American people. By limiting human influence to a minimum wilderness is declared to be "an area where the earth and its community of life are untrammeled by man, where man himself is a visitor who does not remain." (Wilderness Act, 1964, Section 2c). In addition to preserving the natural environment, wilderness is designated to provide "outstanding opportunities for solitude or a primitive and unconfined type of recreation” (Wilderness Act, 1964, Section 2c).

The appropriate management of a wilderness area is guided by the Act, but ultimately also depends on manager's objectives (Wagar, 1974). The tools to manage designated wilderness areas in accordance with legislation are broad. There are direct methods like use limits and indirect methods such as the provision of additional access points to underused areas in order to disperse visitors (Lime \& Stankey, 1971; Lucas, 1973; Wagar, 1974). Authors have frequently stressed that managing wilderness means managing both the natural resource and the people that use the resource for recreation: "Management to protect a degree of solitude must be visitor management." (Lucas, 1973, p.154). This can be challenging because 
underlying visitor motivations lead to differences not only in recreation behavior, but also in the user's expectations and perceptions (Driver \& Tocher, 1970). Generally speaking, wilderness management requires a balance between recreational use, management objectives, and the preservation of the resource as defined by the Wilderness Act of 1964 (Hendee et al., 1978).

Frameworks such as the Limits of Acceptable Change (LAC) have been successfully applied to wilderness management for decades. Such frameworks intend to help managers to make better assessments and decisions in regards to the preservation of wilderness quality and provision of recreation opportunities (Stankey et al., 1984). Cole et al. (1987) provide a whole report on common issues that arise for wilderness managers and suggests a variety of potential management strategies to solve those problems. Even though the limitation of user numbers has always been a widely used method to prevent negative impacts on both the natural resource and the visitor's recreation experience, managers should always carefully consider if this approach is the most effective and efficient method for their wilderness area. Managers also have to evaluate potential impacts of use limits on other areas in the region (McCool, 2000). For effective wilderness management the development of standards that are to be used in on-going inventory and visitor monitoring programs are crucial (Cole et al., 2000; Oye, 2001).

There have been numerous studies on outdoor recreation use in wilderness settings. Marion (1998) found that recreational use in wilderness especially focuses on "water and other scenic attractions in the backcountry" (Marion, 1998, p. 191) and emphasized the importance of active management in order to prevent negative impacts on the natural resource. Traditionally, recreation managers tend to focus resources on those areas that experience higher visitation. This can be difficult in federally designated wilderness areas: According to Merigliano and Smith (2000) wilderness managers are increasingly challenged 
by deciding how to use limited resources to most effectively balance visitor needs and preserve the area's wilderness characteristics.

Some authors suggest such management challenges are likely to become even more complex in the future because of continually visitation caused by better accessibility and information about wilderness recreation (Stankey, 2000). Therefore, it is important to continue to visitor monitoring in wildernesses and to apply pro-active management strategies in order to provide high-quality recreation experiences to visitors while also preserving the outstanding values of the area as defined by the Wilderness Act (Leung \& Marion, 2000).

\section{Comparative Wilderness Recreation Studies}

In a comparative study Stankey (1980) found that visitors across different wilderness areas had similar socio- economic characteristics. The majority was male, highly educated, and there was a wide age range. The sample of visitors in that study participated in a variety of recreation activities, with fishing, photography, and nature study being especially popular. Another comparative study was conducted by Lucas (1980). This study came to very similar results as Stankey (1980). Lucas (1980) analyzed differences in visitor and trip characteristics, attitudes, and preferences in nine wilderness areas in Montana and California. One of the essential findings was that the majority of visits were day trips.

Cole (2001) examined differences between day users and overnight users in seven wilderness settings throughout the US. Even though both user segments tend to be similar in their socio demographic characteristics overnight users reported higher perceived crowding levels than day users. Wilderness characteristics such as opportunities for solitude and experiencing nature appeared to be more important for recreationists who were on an overnight trip.

In a more recent study, Hall and Cole (2007) investigated visitor satisfaction, behavior, perceptions, and motivations in nineteen wilderness areas in Oregon and California. 
It was found that even though numbers of visitors to wilderness areas were increasing, very few recreationists felt crowded. Crowding typically was not found to have a significant effect on overall satisfaction in that study. This was explained by cognitive coping mechanisms, which allowed the recreationists to deal with increasing numbers of visitors recreating in the same wilderness area. The authors suggested a more active management to avoid crowding in wilderness rather than forcing visitors to develop coping behavior (Hall \& Cole, 2007). Regarding differences in importance ratings for wilderness specific site attributes, it has been suggested that there are virtually no difference between users in the western US compared to users in the eastern US (Roggenbuck, Williams, \& Watson, 1993). On the other hand, results from Li et al.'s (2001) study on hunters in Pennsylvania and Colorado indicated that a region's cultural characteristics may have a larger influence on recreation behavior than the visitors' sociodemographic characteristics.

\section{Social Carrying Capacity}

As a result of increased recreational use of public lands, concerns about the impact of higher visitor numbers to those lands and to the recreation experience began to arise in the early 1960s. In 1964, Wagar was the first one to apply the concept of carrying capacity, which before had been widely used in natural science disciplines, to outdoor recreation. In his essay Wagar stated that carrying capacity in outdoor recreation must not just take into account the impact of recreation use on the natural resource, but also on the quality of the visitor's recreation experiences. In one of his later articles he stressed that it is important for managers to evaluate possible effects on whole system of recreation settings before making management decisions that aim at impacting the social carrying capacity of only one wilderness area within that system (Wagar, 1974).

How much is too much? This has been a central question for scientists since the concept of social carrying capacity has been introduced to outdoor recreation research. In 
order to define a recreation area's carrying capacity the three components of this concept must be taken into account: management objectives, visitor attitudes, and recreational impact on the natural resource. It is crucial and difficult to manage an area to increase its capacity without sacrificing quality of the visitor experience, disregarding management objectives, or neglecting negative impacts on the physical environment (Lime \& Stankey, 1971). Applied to wilderness areas in particular, increasing visitation does not just result in a loss of "opportunities for solitude" for the visitors, but may also lead to a decline in the quality of the sensitive natural resource (Hendee et al., 1978).

\section{Measuring Social Carrying Capacity in Wilderness: Visitor Satisfaction, Crowding, and}

\section{Conflict}

As mentioned previously visitor monitoring is critical for defining a wilderness area's social carrying capacity and setting the baseline for management decisions. There are various methods to survey wilderness visitors. Mail- back surveys and self- administered trail registers for instance have been applied for decades (Lucas \& Oltman, 1971). Frissel's and Stankey's (1972) Limits of Acceptable Change was one of the first formal frameworks utilized to define limits and to measure changes on both the physical environment, as well as the visitor experience caused by recreation use. Washburne (1982) claimed that instead of measuring use levels, the establishment of standards and survey of particular conditions would be a more suitable method for managers to decide what conditions are appropriate for a wilderness area.

Social carrying capacity is measured by experience parameters such as visitor satisfaction, crowding and conflict (Shelby \& Heberlein, 1984). According to Shelby and Heberlein, social carrying capacity consists of a descriptive and an evaluative component. The descriptive portion includes factors such as crowding levels, which can be influenced by 
managers (management parameters). Management objectives are an example for the evaluative component.

Perceived crowding is one of the most important parameters to measure social carrying capacity. As perception "refers to the process whereby an individual receives information from the social and physical environments in which he operates, interprets it in the light of his experience and attitudes, and then reacts." (Lime \& Stankey, 1971 p.176), every visitor evaluates encounters with other recreationists differently. When comparing carrying capacity perceptions between two wilderness areas, Stankey (1980) found that recreationists in a high use wilderness were significantly more tolerant of encounters with other visitors than people recreating in a low use wilderness setting. Other studies confirmed these findings and also found high overall satisfaction levels across several wilderness areas in the western US (Lucas, 1980). More recent research has revealed a weak negative correlation between perceived crowding and satisfaction levels of wilderness users. However, the authors of that study stressed that often satisfaction levels are still high even though recreationists perceive crowding. The main component that informed perceived crowding were expectations. If expected levels were exceeded, visitors were more likely to feel crowded (Dawson \& Watson, 2000). Well-informed wilderness management may contribute to stable crowding levels in an area (Bacon et al., 2001).

Since social carrying capacity and its measurements are rather complex, there have been suggestions for improvement for measures of concepts such as satisfaction and crowding. McCool and Lime (2001) recommend changing the question from the rather basic "How much is too much?" to measuring "What are appropriate or acceptable conditions?" Burns et al. (2003) suggest a multiple-item approach to measure the complexity of recreation satisfaction. 
Another important component of social carrying capacity is social conflict. Social conflict in outdoor recreation can occur between recreationists or within a user group. Different motivations to participate in an outdoor recreation activity and diverse goalobjectives that are competitive can result in conflict (Driver \& Tocher, 1970). Jacob and Schreyer (1980) formally defined conflict in an outdoor recreation setting as the goal interference of one recreationist with another visitor's behavior. Other authors who researched conflict in wilderness settings showed that one user group's attitude towards another user group is strongly related to potential conflict between those user segments (Watson et al., 1994). For instance, conflict between hikers and horseback riders or other stock users is often based on the hikers' attitude towards and perceptions of stock users in wilderness settings. The need "for further examination of recreational conflict situations to determine if these conflicts are consistent across areas or situations" (Watson et al., 1994, p.384) is often emphasized.

Studies examining differences in visitor characteristics and social carrying capacity between wilderness areas have resulted in consistent findings. Few differences regarding demographic characteristics, satisfaction, crowding, and conflict were discovered within as well as between the individual studies. Overall it was found that majority of wilderness recreationists are male, white, highly educated, visitor satisfaction is high, levels of perceived crowding and social conflict are low (Hendee et al., 1978; Stankey, 1980; Lucas, 1980; Cole \& Hall, 2008; Palso \& Graefe, 2008).

\section{Motivations}

Motivations are the underlying psychological and physiological forces that lead to a certain human behavior. Humans behave in specific way in the pursuit of goal-objects (Driver $\&$ Tocher, 1970). Research on motivations in outdoor recreations often applies the Recreation Experience Preference (REP) scale, as developed by Driver in 1983. Manfredo et al. (1996) 
conducted a meta-analysis of 36 studies that used REP scale items. The authors grouped individual motivational scale measures like "to experience the peace and calm" into wider domains like "escape physical pressure." Those domains can be summed into categories such as nature, social, escape, fun, and learning. Research in wilderness has shown that those items referring to relaxation, enjoying nature and experiencing solitude are especially important for visitors recreating in these kinds of settings (Graefe et al., 2000; Cole, 2001). Findings such as that one wilderness area's overnight visitors are more likely to be motivated by seeking fun, challenge, or escape than day users are valuable information for recreation managers. As Graefe et al. (2000) suggested, managers can only ensure visitors' needs are met if they know why people recreate in a certain wilderness area or how one user group is different from another.

\section{The Role of Gender in Wilderness Recreation}

Past studies have shown that women traditionally are a minority group in outdoor recreation (Schuster et al., 2003). This has also been found to be true for wilderness recreation in particular (Hendee et al., 1978; Stankey, 1980; Lucas, 1980; Cole \& Hall, 2008).

Henderson (1996) argued that traditionally women were more likely to fulfill domestic household roles, such as mother, housewife, or primary caregiver, which may be one reason for the underrepresentation of females in outdoor recreation. However, participation in outdoor recreation by females, including in wilderness recreation, is increasing (Roggenbuck \& Watson, 1989). A recent study on gender distribution of campers in Canada revealed that the majority of the 1,047 respondents were female (CCRVC, 2014).

Research on the role of gender in outdoor recreation in general has come to rather broad conclusions such as that "all forms of social activities were popular amongst males and females." (Cordell et al., 1999, p.254). Similar to other minority groups, such as older visitors and non- white visitors, women tend to perceive a variety of constraints that keep them from 
participating in outdoor recreation. Safety concerns, gender stereotyping, and lack of funds are examples for such constraints (Johnson et al., 2001). In their study on solo hiking Coble et al. (2003) found that both men and women perceived constraints and fears such as being attacked by other visitors or wildlife, getting lost, or experiencing life threatening emergencies when hiking alone. Female solo hikers were more constrained by fear than their male counterparts. Their biggest fear was getting attacked by another male individual while hiking by themselves, whereas men were more concerned about injuries and life threatening emergencies. Women reportedly "engaged in more avoidance and defensive behaviors to negotiate their fears" (Coble et al., 2003, p.19). A study on ethnical and gender- based diversity in urban park settings, which was partly sponsored by the US Forest Service, found that women were more likely to rate some variables as more important than men. Overall, there were more differences between ethnical groups than between female and male visitors (Ching- hua et al., 2005).

Studies on gender- based differences in recreation behavior in wilderness and nonwilderness settings have produced varying results. Hartmann and Cordell (1989) found there are gender-based differences in participation in outdoor recreation activities in wilderness, particularly in those activities that are physically more demanding or traditionally seen as masculine. More recent research in non- wilderness settings revealed more similarities than differences between males' and females' motivations for bird watching (Sali \& Kuehn, 2006). Research on paddlers showed significant differences between female and male recreationists with regards to motivations and attributes of the site. Females were more likely to be motivated by social aspects, relaxations, and experiencing nature compared to men (Lee et al., 2007). Other authors found that "the differences in leisure patterns between men and women are more contextual than biological" (Henderson, 1996, p. 143). 
There are very few studies that dig deeper into investigating women's wilderness recreation behavior. Borrie et al. (2000) investigated the effect wilderness recreation has on women's everyday life. Because of the lack of a conceptual framework, this research project utilized a qualitative approach to explain the effects. Participants reported positive outcomes including increased self- esteem, authority, freedom, and independence. Authors assumed that these were not just outcomes of wilderness recreation but might also function as motivational factors for women to recreate in wilderness settings. Further research on this issue was suggested (Borrie et al., 2000).

Programs such as Women in Nature or Outdoors Women aim at connecting more women to the outdoors and provide support in overcoming constraints that female users tend to perceive (Yerkes \& Miranda, 1982). More recently, initiatives such as Becoming an Outdoors Woman (BOW) intend to engage more females in traditionally male dominated outdoor recreation activities. Not just do female recreationists learn basic techniques and skills needed for activities such as camping, fly fishing, or hunting, but they are also encouraged to overcome fears and constraints in a friendly and relaxed environment. It has been shown that participation in the program had a long term positive impact on how the women felt about their personal life (Dougherty et al., 2005). Studies on women's participation in all- female outdoor recreation trips revealed that such group focused leisure activities lead to increased self- esteem and empowerment of participants (Mitten, 1992).

McNiel et al. (2012) conducted a study on wilderness recreation advertisements, finding that females were extremely underrepresented. The authors identified potential reasons, including that "wilderness [is] seen as the traditional arena in which men can enact rugged individualism and affirm their masculinity" (McNiel et al., 2012, p.42). The authors argued that the potentially negative image that society has of women, who do not comply with traditional gender roles but participate in adventures in wilderness, is another potential 
constraint for women's engagement in wilderness recreation. Results from Little's (2002) research supported this explanation. Based on findings from this qualitative study on women's participation in adventure recreation, the author concluded that women frequently perceive socio- cultural, self, family and other commitments, as well as technical constraints. 


\section{CHAPTER 3 - METHODOLOGY}

This thesis used data collected in two wilderness areas in the Stanislaus National

Forests and three areas in the Klamath National Forest in California (USFS Region 5: Pacific Southwest), as well as three wilderness areas in the Deschutes and Willamette National

Forests in Oregon (USFS Region 6: Pacific Northwest). Figure 1 and 2 show the location of the National Forests studied in this thesis.

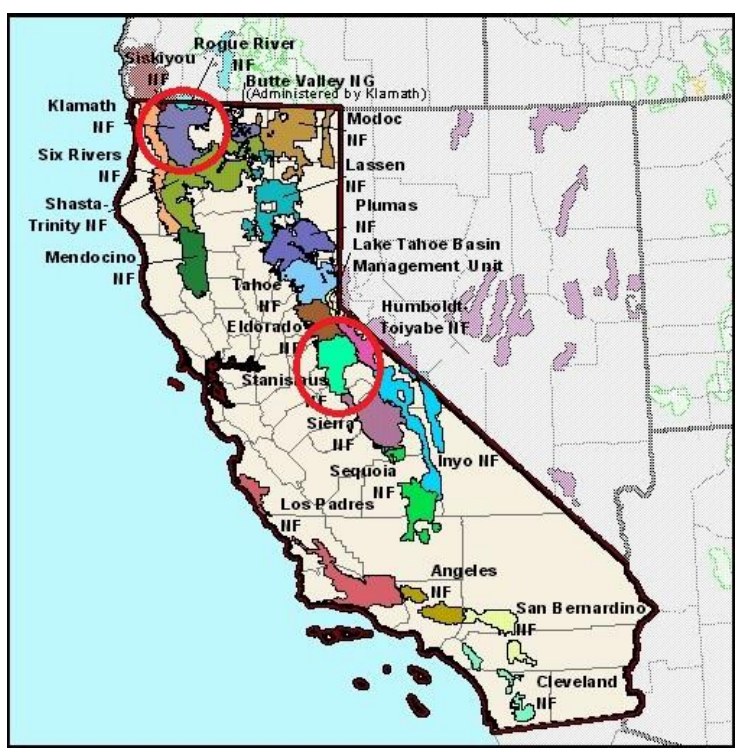

Figure 1:

Klamath and Stanislaus National Forests, CA. (Courtesy of www.fs.fed.us)

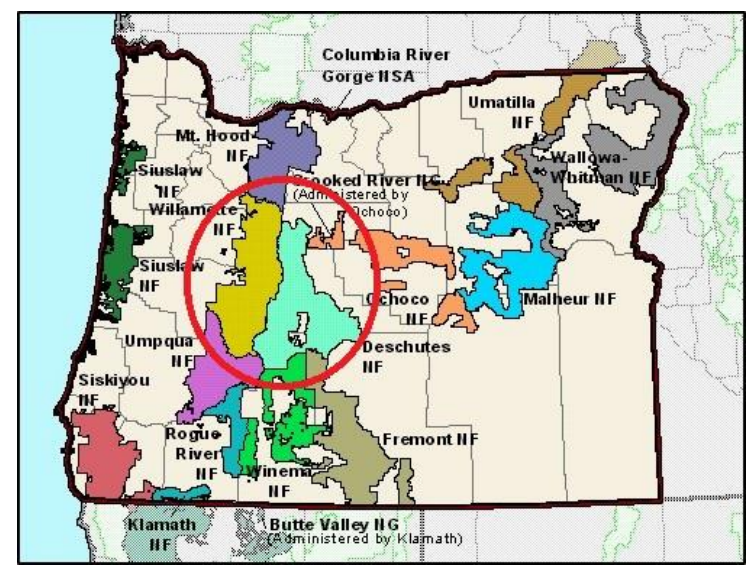

Figure 2:

Deschutes and Willamette National Forests, OR. (Courtesy of www.fs.fed.us)

\section{Study Areas}

Surveys were conducted in the Emigrant Wilderness and the Carson-Iceberg Wilderness on the Stanislaus National Forest in Region 5.

The Emigrant Wilderness, which is bordered by Yosemite National Park in the south, was designated by Congress in 1975. It covers 112,277 acres and is dominated by many lakes, vast meadows, glaciated landscapes, and geologically interesting mountains and ridges.

The Carson-Iceberg Wilderness has a total of 161,181 acres which are evenly split between the Stanislaus National Forest and the Humboldt-Toiyabe National Forest. Data for this study were collected in the Stanislaus National Forest portion only. The Carson-Iceberg Wilderness is characterized by numerous $10,000+$ feet high peaks, stunning granite 
formations, broad rivers, waterfalls and vast meadows. It was designated by Congress in 1984 and is accessible by more than 200 miles of trails.

The second forest in the Pacific Southwest is the Klamath National Forest. Data collection took place in the Marble Mountain, Russian, and Siskiyou Wilderness areas. The Marble Mountain Wilderness was designated by Congress in 1964. With a total of 225,114 acres, it is the largest of the Californian wilderness areas studied in this thesis. The highest peak is Boulder peak ( 8299 feet). The landscape is characterized by vast meadows, streams, and interesting geological features such as the eponymous Marble Mountains.

The Russian Wilderness was designated in 1984 and includes 12,521 acres. Steep slopes, glacier shaped valley, granite peaks (highest: Russian Peak at 8,900 feet), and more than 20 named lakes characterize the landscape. Despite the broad trail network this is a comparatively low use wilderness.

Designated by Congress in 1984, Siskiyou Wilderness encompasses 179,846 acres. This area is dominated by forested ridges and rough peaks, meadows and valleys, mountain lakes and broad rivers. There are some trails leading to lakes, but in large parts of the wilderness trails are nonexistent. Overall, recreation use is low and focused on the trail providing access to the lakes. The Wilderness stretches across three National Forests: Klamath, Six Rivers, and Siskiyou National Forests. Data collection for this study was concentrated on the Klamath National Forest portion of the Siskiyou Wilderness.

The three Wilderness areas surveyed in the Oregon National Forests were Three Sisters, Mt. Jefferson, and Mt. Washington Wilderness. All three wilderness areas have portions in both the Deschutes and the Willamette National Forests and are crossed by the renowned Pacific Crest Trail.

Encompassing 283,630 acres, the highly used Three Sisters Wilderness, designated by Congress in 1964, is the largest of the Oregonian Wilderness areas analyzed in this thesis. It 
is a volcanic landscape, shaped by glaciers and dominated by the eponymous snow covered Three Sisters, all of which are above 10,000 feet. Numerous stunning lakes, streams, and alpine meadows are connected by 260 miles of trails.

The north border of the Three Sisters Wilderness is the Mt Washington Wilderness, designated in 1964. It encompasses 54,542 acres of terrain, with distinctive geological features. The eruption of the Belknap Crater, about 1,500 years ago, resulted in one of the largest lava fields in the US. The setting includes 28 lakes, many of them accessible via trails.

The Mt Jefferson Wilderness, designated by Congress in 1968, includes Mt Jefferson (10,497 feet). It is surrounded by more than 150 lakes, wide open land and meadows. Recreational use of the 190 mile trail system is very high in these 104,523 acres of wilderness.

\section{Survey Instrument}

Two individual survey instruments from the two independent studies in the national forest of Oregon and California were combined for the purpose of this thesis. Only questions that appeared on both surveys instruments were utilized for analyses. The set of questions used for this thesis can be divided into six categories: demographic information, trip characteristics, motivations, satisfaction items, crowding and conflict.

Socio demographics included age, gender, home country, level of education, annual household income, group composition, and information regarding race and ethnicity. Trip type, recreation activities participated in, and primary activities were recorded for describing trip characteristics. Since the data collected originate from two independent survey instruments, some activities were adjusted for the final database this thesis is based on. Camping in pre-existing sites and primitive or dispersed camping were grouped into one variable camping. Recreation activities that only appeared on one of the two survey 
instruments were transferred to the category other and were then specified in an open- ended variable. This mainly applied to horseback riding.

Motivation items were measured on a scale of 1 to 5 (where 1 means not at all important and 5 means extremely important). The items on that list were based on the Recreation Experience Preference item pool first proposed by Driver (1983). Visitors were also asked to select the most important reason to visit the wilderness from a list. These included the enjoyment of the physical environment, the recreation activity, social reasons, and proximity to home. Variations of those motivation measures have been utilized in previous studies in outdoor recreation research (Manfredo et al., 1996; Cole, 2001).

A 5- point Likert scale was utilized for a single- item measurement of overall satisfaction in the Deschutes and Willamette National Forests. A 6-point scale was applied for the measuring the same variable in the Klamath and Stanislaus National Forests. Lower scores indicate less satisfaction, fives and sixes representing very high overall satisfaction. To make this variable usable for this thesis, the 5- and 6- point scales were transformed into a 3point scale $(1=$ not satisfied, $3=$ very satisfied $)$. This is a common strategy that is often applied in research on service quality for simplifying data on customer satisfaction for analytical purposes (Sureshchandar et al., 2002). Vaske and Roemer (2013) utilized the same approach for a comparative study on overall satisfaction of consumptive and nonconsumptive recreationists.

Additional satisfaction measures included satisfaction with specific quality attributes. Recreationists in both regions were asked to indicate their level of satisfaction with a list of attributes using a 5- point scale ( $1=$ strongly disagree, $5=$ strongly agree $)$. Visitors had the opportunity of choosing a not applicable option for attributes that did not apply to their recreation experience. These scales have been applied in numerous previous recreation studies (Lucas, 1980; Burns, 2000). Finally, visitors rated the quality of four satisfaction 
domains on a 5-point scale (1=awful, 5=excellent, with a not applicable option). The satisfaction domains were developed by Parasuraman et al. (1988) and have been utilized in numerous outdoor recreation research projects since then (Burns et al., 2003).

A set of variables were employed to measure crowding. Visitors were asked to indicate perceived crowding levels on a 9 - point scale $(1=$ not at all crowded, $9=$ extremely crowded). Researchers in outdoor recreation have used this scale frequently since it was first proposed by Heberlein and Vaske (1977). Interviewees were also asked to report encounters with other groups, time spent in sight of other parties, and to compare experienced crowding with their expected crowding. Additionally, acceptable percentages of time to see other groups, acceptable numbers of encounters with other recreationists, and preferred group size to visit wilderness were recorded. Previous studies have applied these same variables, which have proven to be appropriate measurements of expected and perceived crowding levels (Shelby et al., 1989).

Finally, if a visitor reported that social conflict occurred during the visit, interviewees were asked an open ended question to specify the nature of the conflict.

\section{Data Collection}

On-site surveys were used to conduct data in all wilderness areas. For each of the individual wilderness areas, interviewers sampled recreationists at different, mainly high- use trailheads that are access points for the area.

Surveys were conducted in the Klamath and Stanislaus National Forests from June through October 2010. A total of 396 surveys were conducted for the three wilderness areas in the Klamath National Forest. The total number of interviews in the Emigrant and CarsonIceberg Wilderness, in the Stanislaus National Forest, was 956.

A total of 587 on-site surveys were conducted in the wilderness areas in the Deschutes National Forests from May through August 2010. In the same time period, 620 surveys were 
conducted at access points to the same wilderness areas in the Willamette National Forest. The total number of usable data points from all eight wilderness areas in the four National Forests used in this thesis is 2,559 (see Table 1).

Table 1. Study Areas and Number of Surveys.

\begin{tabular}{llcc}
\hline \multicolumn{1}{c}{ Wilderness } & \multicolumn{1}{c}{ Forest } & \# of surveys & $\begin{array}{c}\text { Total \# surveys in } \\
\text { Wilderness areas by region }\end{array}$ \\
\hline $\begin{array}{l}\text { Three Sisters } \\
\text { Wilderness } \\
\text { Mt Jefferson } \\
\text { Wilderness }\end{array}$ & Deschutes/Willamette & 684 & 1,207 \\
$\begin{array}{l}\text { Mt Washington } \\
\text { Wilderness }\end{array}$ & Deschutes/Willamette & 106 & \\
\hline $\begin{array}{l}\text { Emigrant } \\
\text { Wilderness }\end{array}$ & Stanislaus & 417 & \\
$\begin{array}{l}\text { Carson- Iceberg } \\
\text { Wilderness }\end{array}$ & Stanislaus & 632 & 956 \\
\hline $\begin{array}{l}\text { Marble } \\
\text { Mountain }\end{array}$ & Klamath & 324 & 396 \\
Russian & Klamath & 167 & \\
Siskiyou & Klamath & 111 & \\
\hline
\end{tabular}

\section{Testing of the Research Questions}

The Statistical Packages for the Social Sciences (SPSS) was used to analyze the data for this thesis. In order to test the research questions, two individual SPSS databases were merged into one. Variables that did not appear in both databases were eliminated. Some variables needed recoding as the different survey instruments utilized different scales. One example is overall satisfaction. One survey instruments used a 5-point Likert scale, the other one a 6- point scale. In order to answer research questions regarding satisfaction levels in this thesis, that variable was recoded into a three point scale: $1=$ not satisfied, $2=$ somewhat satisfied, $3=$ very satisfied . The analyses conducted were the following: 
RQ1: What does the sample of visitors look like across the wilderness areas?

Socio- demographic variables included age group, gender, and others. Variables such as trip type, recreation activities, and primary activity were utilized to describe group characteristics. Frequencies were calculated, and means and valid percentages were analyzed.

RQ2: What motivates visitors to recreate in the wilderness areas?

Frequencies, means, and valid percentages were run and reported for the motivation variables.

RQ3: What is the satisfaction level of respondents across the wilderness areas?

A set of variables were used to measure overall satisfaction and satisfaction with individual items. Again, analysis included frequencies, mean scores, and valid percentages. RQ4: What are the levels of crowding and conflict across the wilderness areas?

For the conflict variable and the set of crowding variables frequencies, means, and valid percentages were examined.

RQ5: Are there significant differences in visitors' motivations, satisfaction, and perceived crowding levels between the wilderness areas in the Deschutes-Willamette, Klamath, and Stanislaus National Forests?

One way ANOVAs and cross tabulations were utilized to examine differences in motivations, satisfaction, crowding, and conflict between the three regions.

RQ 6: Are there significant differences in trip characteristics, motivations, satisfaction, crowding and conflict between female and male visitors?

Frequencies and valid percentages were applied to describe the proportions of female and male visitors for each region's sample.

A series of independent samples t-tests and cross tabulations were conducted. The gender variable was run against measures of motivations, perceived crowding, socio- 
demographics, and trip type. Significant differences between males and females indicated gender- specific characteristics.

RQ 6a: Can a typology be derived from variables such as motivations, satisfaction levels, perceived crowding and trip type for female and male visitors?

Independent t- tests were utilized to run the gender variable against those motivation, satisfaction, and crowding variables, that produced significant results in research question 6 , for each of the three regions. 


\section{CHAPTER 4 - RESULTS}

In this chapter, results of the statistical analysis for each individual research question will be presented. First, sociodemographic information and trip characteristics of the sample are described. Second, motivations, satisfaction, crowding, and conflict levels across all wilderness areas are analyzed. Third, differences between the three regions with regards to those variables are examined. Finally, potential differences between female and male visitors are investigated to potentially develop a typology for the two gender based user groups.

\section{RQ1: What does the sample of visitors look like across the wilderness areas?}

Table 2 and 3 show the results of the descriptive analysis of the sociodemographic variables. Frequencies and valid percentages were calculated for gender, age, education level, annual household income, country of residency, and race.

Two thirds of the respondents were male (66.9\%) and one third were female (33.1\%). Visitors were relatively evenly distributed across all seven age categories. Most visitors were between 51 and 60 years old (23.0\%). The smallest portions of the sample were in the over 70 age group (6.8\%) and between the ages of 16 and 20 (4.9\%).

Regarding education levels were high, less than one third of the respondents held a high school, technical school, or 2 year college degree (31.0\%). A little over one third had a Bachelor's degree (36.9\%), almost one quarter held a Master's degree (22.8\%), and 9.3\% had a $\mathrm{Ph} . \mathrm{D}$. or professional degree.

The majority of visitors self-identified as members of medium annual household income groups. Only a small portion of recreationists made an annual household income of $\$ 150,000$ or more (14.2\%). More than half were in the $\$ 50,000-150,000$ income groups (54.6\%) and about one third indicated a household income of $\$ 50,000$ or less $(31.2 \%)$. 
Table 2: Sociodemographic Profile of Respondents.

\begin{tabular}{|c|c|c|}
\hline & Frequencies & Valid Percent \\
\hline \multicolumn{3}{|l|}{ Gender } \\
\hline Female & 824 & 33.1 \\
\hline Male & 1,668 & 66.9 \\
\hline \multicolumn{3}{|l|}{ Age } \\
\hline $16-20$ & 121 & 4.9 \\
\hline $21-30$ & 335 & 13.5 \\
\hline $31-40$ & 351 & 14.2 \\
\hline $41-50$ & 483 & 19.5 \\
\hline $51-60$ & 570 & 23.0 \\
\hline $61-70$ & 445 & 18.0 \\
\hline over 70 & 169 & 6.8 \\
\hline \multicolumn{3}{|l|}{ Education } \\
\hline High school or less & 350 & 14.2 \\
\hline Technical school/ 2 year college & 416 & 16.8 \\
\hline Bachelor's degree & 911 & 36.9 \\
\hline Master's degree & 562 & 22.8 \\
\hline Ph.D./ Professional degree & 230 & 9.3 \\
\hline \multicolumn{3}{|l|}{ Annual household income } \\
\hline$\$ 25 \mathrm{k}$ or less & 281 & 12.9 \\
\hline$\$ 25 \mathrm{k}-50 \mathrm{k}$ & 398 & 18.3 \\
\hline$\$ 50 \mathrm{k}-100 \mathrm{k}$ & 755 & 34.6 \\
\hline$\$ 100 \mathrm{k}-150 \mathrm{k}$ & 436 & 20.0 \\
\hline$\$ 150 \mathrm{k}-200 \mathrm{k}$ & 171 & 7.8 \\
\hline$\$ 200 \mathrm{k}$ or over & 139 & 6.4 \\
\hline
\end{tabular}

The vast majority of the wilderness recreationists were US residents $(95.4 \%)$. Very few visitors were visiting from another country (4.6\%). Nearly all of the respondents were non-Hispanic, Latino, or Spanish Caucasians (98.6\%). Significantly smaller portions of the sample represented a diversity of other racial groups such as American Indian and Alaskan Native (6.6\%), Chinese (3.9\%), and Black/ African American (2.9\%). Respondents were allowed to choose more than one answer choice for answering the racial identity question. 
Table 3: Sociodemographic Profile of Respondents Continued.

\begin{tabular}{lcc}
\hline & Frequencies & Valid Percent \\
\hline US Resident & 772 & 95.4 \\
Visitor from another country & 37 & 4.6 \\
Hispanic, Latino, or Spanish origin & 122 & 5.2 \\
Yes & 2,226 & 94.8 \\
No & & \\
Race & 2347 & 98.6 \\
White & 19 & 2.9 \\
Black or African American & 45 & 6.6 \\
American Indian or Alaska Native & 4 & $<1.0$ \\
Asian Indian & 14 & 2.1 \\
Japanese & 5 & $<1.0$ \\
Native Hawaiian & 26 & 3.9 \\
Chinese & 5 & $<1.0$ \\
Korean & 13 & 2.0 \\
Filipino & 7 & 1.1 \\
Vietnamese & 3 & $<1.0$ \\
Samoan & 16 & 2.4 \\
Other Asian or Pacific Islander & & \\
\hline
\end{tabular}

Frequencies, valid percentages, and means were calculated to investigate trip type, trip length, and group characteristics (see Tables 4 - 6). As shown in table 4, the sample was evenly split between day users (49.3\%) and overnight users (50.7\%).

Table 4: Overnight and Day Use.

\begin{tabular}{lcc}
\hline & Frequencies & Valid Percent \\
\hline Day trip & 1,254 & 49.3 \\
Overnight trip & 1,289 & 50.7 \\
\hline
\end{tabular}

Overnight users spent an average of 2.28 days in wilderness and day users recreated for 4.64 hours on average (see Table 5).

On average there were 2.04 children under 16 years of age and 1.37 vehicles per group. There was one group consisting of ninety children and ten adults, who went on a two 
day backpacking trip in the Russian Wilderness in the Klamath National Forest. This extreme outlier was excluded in the analysis.

Most respondents recreated in groups of 3 . The average group size was 3.75 persons (see Table 6).

Table 5: Trip Length and Group Characteristics.

\begin{tabular}{lc}
\hline & Mean \\
\hline Days in Wilderness & 2.28 \\
Hours in Wilderness & 4.64 \\
Children in group & 2.04 \\
Number of vehicles per group & 1.37 \\
\hline
\end{tabular}

Table 6: Group Size.

\begin{tabular}{|c|c|c|}
\hline Group size & Frequencies & Valid Percent \\
\hline Small (5 people or less) & 2,089 & 83.7 \\
\hline Medium (6-15people) & 375 & 13.0 \\
\hline Large (16 - 25 people) & 21 & $<1$ \\
\hline \multirow[t]{2}{*}{$>25$ people } & 10 & $<1$ \\
\hline & Median $=3.00$ & Mean $=3.75$ \\
\hline
\end{tabular}

During their trip to the wilderness visitors participated in a variety of outdoor recreation activities. As shown in Table 7, hiking or walking was the most popular primary activity (39.9\%), closely followed by backpacking, camping (31.3\%). Another common primary activity was viewing natural features such as scenery, wildlife, birds, flowers, fish, etc. $(7.2 \%)$ 


\begin{tabular}{lcc}
\hline & Frequencies & Valid Percent \\
\hline Backpacking, camping & 720 & 31.3 \\
Viewing natural features such as scenery, wildlife, birds, & 165 & 7.2 \\
flowers, fish, etc. & 8 & $<1.0$ \\
Visiting historic and prehistoric sites/ areas & 14 & $<1.0$ \\
Nature study & 95 & 4.1 \\
General/other- relaxing, hanging out, escaping heat, noise, & & \\
etc. & 98 & 4.3 \\
Fishing- all types & 74 & 3.2 \\
Hunting- all types & 917 & 39.9 \\
Hiking or walking & 2 & $<1.0$ \\
Nonmotorized water travel (kayaking, rafting, canoe, etc.) & 28 & 1.2 \\
Other nonmotorized activities (swimming, games, sports) & 9 & $<1.0$ \\
Gathering mushrooms, berries, firewood, or other natural & & \\
products & 46 & 2.0 \\
Climbing & 122 & 5.3 \\
Other & & \\
\hline
\end{tabular}

\section{RQ2: What motivates visitors to recreate in the wilderness areas?}

Recreationists were asked to rate the importance of nine motivational items on a five point scale (where 1 means not at all important and 5 indicates extremely important).

Percentages for each response category and mean scores for each item on the list were calculated (see Table 8).

Of the nine items presented to the visitor, those describing the physical setting, to be outdoors $($ mean $=4.74)$ and to experience natural surroundings $($ mean=4.73), showed the highest average scores. Over $90 \%$ of respondents indicated that each of these two motivational items was a very important or extremely important reason for recreating in wilderness.

Catharsis items such as for relaxation (mean=4.48) and to get away from the regular routine (mean $=4.57$ ) were also evaluated as very important or extremely important by approximately $90 \%$ of the respondents. For physical exercise (mean=4.27), to be with my 
friends $($ mean=4.09), and for the challenge or sport $($ mean=4.02) were also very important motivations for wilderness recreation.

The locus of control item to develop my skills (mean=3.55) and the second social item for family recreation (mean $=3.70$ ) were considered as the least important motivational factors for visiting the wilderness areas. Each of the two items reached very important and extremely important scores from less than two thirds of respondents.

Table 8: Motivations.

\begin{tabular}{lcccccc}
\hline Motivational item & $\begin{array}{c}\text { Not at all } \\
\text { important }\end{array}$ & $\begin{array}{c}\text { Somewhat } \\
\text { important }\end{array}$ & $\begin{array}{c}\text { Moderately } \\
\text { important }\end{array}$ & $\begin{array}{c}\text { Very } \\
\text { important }\end{array}$ & $\begin{array}{c}\text { Extremely } \\
\text { important }\end{array}$ & Mean \\
\hline To be outdoors & $<1$ & $<1$ & 1.8 & 20.9 & 76.9 & 4.74 \\
To experience natural & $<1$ & $<1$ & 2.8 & 19.7 & 77.1 & 4.73 \\
surroundings & $<1$ & 1.4 & 8.1 & 28.2 & 61.6 & 4.48 \\
For relaxation & $<1$ & 1.0 & 6.0 & 25.1 & 67.2 & 4.57 \\
To get away from the & 13.0 & 8.0 & 15.5 & 23.6 & 39.9 & 3.70 \\
regular routine & 6.0 & 5.0 & 13.4 & 25.2 & 50.4 & 4.09 \\
For family recreation & 3.5 & 5.9 & 20.0 & 26.5 & 44.0 & 4.02 \\
To be with my friends & 1.9 & 3.3 & 13.0 & 29.8 & 52.1 & 4.27 \\
For the challenge or & 9.2 & 13.5 & 24.1 & 19.7 & 33.5 & 3.55 \\
sport & & & & & & \\
For physical exercise & To develop my skills & & & & &
\end{tabular}

In addition to the battery of motivational items, recreationists were asked to identify their primary reason for their wilderness visit (see Table 9). Most respondents stated I enjoy the place itself (38.5\%) and it is a good place for the outdoor recreation activities I enjoy $(38.4 \%)$ as the most important reason for the visit. Social components such as spending time with companions $(17.7 \%)$ and the proximity of the wilderness area to the visitor's home (5.4\%) showed weaker relevance for respondents. 
Table 9: Primary Reason to Visit.

\begin{tabular}{lcc}
\hline Primary Reason to Visit & Frequencies & Valid Percent \\
\hline I enjoy the place itself & 953 & 38.5 \\
It is a good place for the outdoor activities I enjoy & 951 & 38.4 \\
I wanted to spend more time with my companions & 437 & 17.7 \\
It was close to home & 133 & 5.4 \\
\hline
\end{tabular}

\section{RQ3: What is the satisfaction level of respondents across the wilderness areas?}

Both overall satisfaction and satisfaction with quality and trip attributes were measured. As stated earlier, different overall satisfaction scales were applied in the individual survey instrument in the three regions. The 5-point and 6-point scales were transformed into a 3-point scale for the purpose of this thesis. Frequencies, valid percentages, as well as means were calculated (see Table 10).

The vast majority of visitors were very satisfied with their recreation experience in the wilderness areas (92.4\%). Only a few respondents indicated they were only fairly satisfied $(6.5 \%)$ or not satisfied with their visit (1.1\%). In general, overall satisfaction levels are very high across all wilderness areas (mean=2.91).

Table 10: Overall Satisfaction.

\begin{tabular}{lcc}
\hline Overall Satisfaction (recoded) & Frequencies & Valid Percent \\
\hline Not satisfied & 29 & 1.1 \\
Fairly satisfied & 163 & 6.5 \\
Very satisfied & 2,333 & 92.4 \\
& & Mean $\mathbf{= 2 . 9 1}$ \\
\hline
\end{tabular}

In addition to overall satisfaction measures, visitors were asked to rate their satisfaction with a number of quality attributes (see Table 11). The analysis of percentages for each unit, as well as the calculation of mean scores, revealed that respondents overall evaluated all quality attributes as very good. Less than one percent rated each individual item as awful, no more than $7.5 \%$ of respondents assessed an item as fair. 
Overall, visitors were most satisfied with the quality of wilderness experience (mean=4.42). Environmental conditions $($ mean=4.40), and quiet or solitude $($ mean=4.34). Lack of human influence (mean=3.94) showed somewhat lower ratings on average.

Table 11: Satisfaction with Quality Attributes.

\begin{tabular}{|c|c|c|c|c|c|c|c|}
\hline \multirow[t]{2}{*}{ Quality attribute } & Awful & Fair & Good & $\begin{array}{l}\text { Very } \\
\text { good }\end{array}$ & Excellent & N/A & \multirow[t]{2}{*}{ Mean } \\
\hline & \multicolumn{6}{|c|}{ - } & \\
\hline Quiet or solitude & $<1$ & 3.8 & 12.5 & 28.1 & 54.8 & $<1$ & 4.34 \\
\hline $\begin{array}{l}\text { Lack of human } \\
\text { influence }\end{array}$ & $<1$ & 7.5 & 21.0 & 36.9 & 32.8 & 1.0 & 3.94 \\
\hline Wilderness experience & $<1$ & 2.0 & 10.6 & 30.2 & 56.5 & $<1$ & 4.42 \\
\hline $\begin{array}{l}\text { Environmental } \\
\text { conditions }\end{array}$ & $<1$ & 1.9 & 10.7 & 32.0 & 54.5 & $<1$ & 4.40 \\
\hline
\end{tabular}

Finally, visitor satisfaction was quantified by a series of statements about the wilderness recreation experience. Respondents indicated their level of agreement on a 6 point scale, which included a not applicable option. Percentages for each category and means were calculated (see Table 12).

As with previously analyzed satisfaction measures all mean scores showed strong agreement that visitor expectations were met. Virtually all respondents agreed or strongly agreed $(98.0 \%)$ that they thoroughly enjoyed their visit to the wilderness (mean=4.69). An almost equally large percentages $(94.2 \%)$ indicated agreement that their trip to this wilderness was worth the money I spent on it (mean= 4.68). Visitors generally agreed that this wilderness and its surroundings are in a good condition (mean=4.30). Approximately one tenth of the sample was disappointed with some aspects of their visit (mean $=1.87$ ). 
Table 12: Level of Agreement with Trip Attributes.

\begin{tabular}{|c|c|c|c|c|c|c|c|}
\hline \multirow[t]{2}{*}{ Trip attribute } & $\begin{array}{l}\text { Strongly } \\
\text { disagree }\end{array}$ & Disagree & Neutral & Agree & $\begin{array}{l}\text { Strongly } \\
\text { agree }\end{array}$ & N/A & Mean \\
\hline & \multicolumn{7}{|c|}{------------------------Percent------------------------- } \\
\hline $\begin{array}{l}\text { I thoroughly enjoyed my } \\
\text { visit to this wilderness. }\end{array}$ & $<1$ & $<1$ & 1.5 & 26.4 & 71.6 & --- & 4.69 \\
\hline $\begin{array}{l}\text { My trip to this wilderness } \\
\text { was well worth the money } \\
\text { I spent to take it. }\end{array}$ & $<1$ & $<1$ & 3.9 & 21.5 & 72.7 & 1.1 & 4.68 \\
\hline $\begin{array}{l}\text { I was disappointed with } \\
\text { some aspects of my visit to } \\
\text { this wilderness. }\end{array}$ & 48.8 & 27.8 & 10.9 & 8.7 & 2.5 & 1.4 & 1.87 \\
\hline $\begin{array}{l}\text { This wilderness and its } \\
\text { surroundings are in good } \\
\text { condition. }\end{array}$ & $<1$ & 2.7 & 7.5 & 43.6 & 44.7 & $<1$ & 4.30 \\
\hline
\end{tabular}

\section{RQ4: What are the levels of crowding and conflict across the wilderness areas?}

Several question on the survey aimed at measuring crowding and conflict levels.

As with the satisfaction measures, the variables assessing conflict and crowding were analyzed through the use of descriptive statistics such as frequencies, valid percentages and mean scores.

First, expected and perceived crowding levels were evaluated (see Table 13). Almost half of the sample indicated the perceived crowding matched their expectations (45.5\%). Just over one quarter saw fewer people during their wilderness trip than they initially expected $(27.8 \%)$ and less than one quarter saw more people than expected (22.6\%). A small proportion of respondents did not have any expectations with regards to crowding levels (4.1\%).

Overall, visitors did not feel crowded while recreating in wilderness (mean=2.25). The number of other visitors resulted in over four fifths of interviewees not feeling crowded at all $(82.0 \%)$ and less than 5\% perceived the actual crowding levels as moderately crowded $(4.4 \%)$ or extremely crowded $(<1 \%)$. 
Table 13: Expected and Perceived Crowding.

\section{Frequencies}

How did the number of people you saw compare

with what you expected to see?

A lot less than you expected

300

401

A little less than you expected

About what you expected

A little more than you expected

A lot more than you expected

You didn't have any expectations

How crowded did you feel during this visit?

Not at all crowded

Slightly crowded

Moderately crowded

Extremely crowded
1,144

373

195

103

2,018

323

109

11
Valid Percent

45.5

14.8

7.8

4.1

82.0

4.4

$<1$

Mean $=2.25$

Actual and preferred crowding were measured by group encounters and time spent in sight of other groups (see Table 14).

On average, respondents spent $16.5 \%$ of their time in wilderness in sight of other groups. The average acceptable percentage of time in sight of other groups was slightly higher $(22.0 \%)$. Visitors encountered just over five other groups during their visit (mean=5.13), which is slightly less than the indicated acceptable number of group encounters $($ mean $=5.61)$.

Table 14: Actual and Preferred Crowding.

\begin{tabular}{lc}
\hline & Mean \\
\hline Percent of time in sight of other groups & 16.5 \\
Acceptable percentage of time in sight of other groups & 22.0 \\
Number of group encounters & 5.13 \\
Acceptable number of group encounters & 5.61 \\
\hline
\end{tabular}


Third, the level of agreement with crowding and conflict attributes was quantified (see Table 15).

More than $90 \%$ of respondents agreed or strongly agreed that they could find places to recreate without feeling crowded (mean=4.50) and without conflict from other visitors (mean=4.57). Visitors disagreed with statements such as that they avoided some places at this wilderness because there were too many people there $($ mean=2.09), that the number of people at this wilderness reduced their enjoyment (mean=1.90), and that the behavior of other visitors at this wilderness interfered with the quality of their recreation experience (mean=1.76). However, between $7.2 \%$ and $17.5 \%$ of interviewees still agreed with each of the last three attributes. Respondents neither agreed nor disagreed that the number of people at this wilderness increased their enjoyment (mean=2.95). Even though the majority of the sample (42.1\%) expressed neutral attitudes towards this statement, a little over one quarter reported agreement $(26.1 \%)$ and disagreement $(28.1 \%)$ that their enjoyment was increased due to the number of visitors at the wilderness. 
Table 15: Level of Agreement with Crowding and Conflict Attributes.

\begin{tabular}{|c|c|c|c|c|c|c|c|}
\hline \multirow[t]{2}{*}{ Attribute } & $\begin{array}{l}\text { Strongly } \\
\text { disagree }\end{array}$ & Disagree & Neutral & Agree & $\begin{array}{c}\text { Strongly } \\
\text { agree }\end{array}$ & N/A & Mean \\
\hline & \multicolumn{7}{|c|}{-----------------------'Percent----------------------- } \\
\hline $\begin{array}{l}\text { I had the opportunity to } \\
\text { recreate without feeling } \\
\text { crowded. }\end{array}$ & $<1$ & 1.9 & 5.2 & 32.5 & 59.7 & $<1$ & 4.50 \\
\hline $\begin{array}{l}\text { I could find places to } \\
\text { recreate without conflict } \\
\text { from other visitors. }\end{array}$ & $<1$ & $<1$ & 4.4 & 29.3 & 64.5 & $<1$ & 4.57 \\
\hline $\begin{array}{l}\text { I avoided some places at } \\
\text { this wilderness because } \\
\text { there were too many } \\
\text { people there. }\end{array}$ & 43.6 & 24.4 & 13.3 & 13.5 & 4.0 & 1.3 & 2.09 \\
\hline $\begin{array}{l}\text { The number of people at } \\
\text { this wilderness reduced } \\
\text { my enjoyment. }\end{array}$ & 44.9 & 28.9 & 16.7 & 6.4 & 1.9 & 1.2 & 1.90 \\
\hline $\begin{array}{l}\text { The behavior of other } \\
\text { people at this wilderness } \\
\text { interfered with the quality } \\
\text { of my experience. }\end{array}$ & 51.9 & 26.5 & 12.2 & 5.2 & 2.0 & 2.2 & 1.76 \\
\hline $\begin{array}{l}\text { The other people at this } \\
\text { wilderness increased my } \\
\text { enjoyment. }\end{array}$ & 12.0 & 16.1 & 42.1 & 17.1 & 9.0 & 3.8 & 2.95 \\
\hline
\end{tabular}

Next, frequencies and valid percentages for the preferred group size were calculated (see Table 16).

The vast majority of the sample preferred to recreate in small groups of five or less people $(81.9 \%)$ or medium groups of six to fifteen people $(12.6 \%)$. Few respondents favored large groups of sixteen to twenty-five people $(<1 \%)$, and a small proportion of the sample indicated no preferences with regards to group size (4.5\%).

Table 16: Preferred Group Size.

\begin{tabular}{lcc}
\hline Group size & Frequencies & Valid Percent \\
\hline Small (5 people or less) & 2,055 & 81.9 \\
Medium (6-15 people) & 317 & 12.6 \\
Large (16 - 25 people) & 23 & $<1$ \\
Makes no difference to me & 114 & 4.5 \\
\hline
\end{tabular}


Lastly, social conflict with other recreationists was analyzed through calculation of frequencies and valid percentages (see Table 17).

Conflict was essentially non- existent in the wilderness areas studied in this thesis. Only $2.1 \%$ of visitors indicated they experienced some sort of social conflict with other groups recreating in the wilderness, while the remaining $97.9 \%$ reported that they did not have any conflict with other parties.

Table 17: Social Conflict.

\begin{tabular}{lcc}
\hline & Frequencies & Valid Percent \\
\hline Did you have any conflict with other parties? & & \\
Yes & 54 & 2.1 \\
No & 2,468 & 97.9 \\
\hline
\end{tabular}

RQ5: Are there significant differences in visitors' motivations, satisfaction, and perceived crowding levels between the wilderness areas in the Deschutes-Willamette, Klamath, and Stanislaus National Forests?

A one way analysis of variance (ANOVA) was utilized to analyze potential differences in visitors' motivations, satisfaction, and perceived crowding levels in the wilderness areas in the three regions (Deschutes- Willamette National Forest, Klamath National Forest, Stanislaus National Forest). In order to further investigate the nature of the statistical differences, a Tukey's HSD post hoc test was conducted for the variables that produced significant results between the three regions.

First, differences in motivations between the three regions were examined (see Table 18). Visitors in all three regions were more frequently motivated by catharsis items and items that describe the physical setting. Of the nine items on the list, eight displayed significant values $(\mathrm{p}<.05)$. The only item, whose importance was not rated significantly different by the respondents in the three regions was to be outdoors. This item was evaluated as extremely important by visitors in the Deschutes- Willamette National Forests (mean=4.74), the 
Stanislaus National Forest (mean=4.74), and the Klamath National Forest (mean= 4.75), $(\mathrm{F}=0.96 ; \mathrm{p}>.05)$

Stanislaus National Forest respondents (mean=4.58) rated for relaxation as more important than visitors to the wilderness areas in the Deschutes-Willamette National Forests $(m e a n=4.43)$ and the Klamath National Forest (mean=4.41), $(\mathrm{F}=12.223 ; \mathrm{p}<.001)$. To experience natural surroundings was of greater importance to the recreationists in the Deschutes-Willamette National Forests $($ mean $=4.73)$ and the Stanislaus National Forest (mean=4.76), compared to those recreating in the wilderness areas in northern California (mean=4.67), $(\mathrm{F}=4.260 ; \mathrm{p}<.05)$. To get away from the regular routine was assessed as more relevant to recreationists in the wilderness areas in the Stanislaus National Forest (mean=4.67) than to visitors in the Deschutes-Willamette National Forests (mean=4.54). The Deschutes-Willamette National Forest visitors rated this motivational item significantly higher than the wilderness recreationists in the Klamath National Forest (mean=4.44), $(\mathrm{F}=16.882 ; \mathrm{p}<.001)$.

The same was true for family recreation: This item was more relevant to respondents in the Stanislaus National Forest (mean= 3.85) than it was to respondents in the Oregon National Forests (mean=3.68), who rated it higher than the wilderness users in the Klamath National Forest (mean=3.38), $(\mathrm{F}=15.286 ; \mathrm{p}<.001)$. To be with my friends was a less important reason to visit the wilderness for the recreationists in the Klamath (mean=3.90) and Deschutes-Willamette National Forests (mean=4.00) than for the respondents in the Stanislaus National Forest $($ mean=4.28), $(\mathrm{F}=20.981 ; \mathrm{p}<.001)$.

For the challenge or sport played a more important role as a motivating factor for wilderness users in the Stanislaus National Forest (mean=4.14) compared to the areas in the Deschutes-Willamette National Forests (mean=4.00). Visitors in the Klamath National Forest rated this items significantly lower $($ mean $=3.76)$ than the respondents from the other two 
regions, $(\mathrm{F}=16.458 ; \mathrm{p}<.001)$. Moreover, wilderness users in the Klamath National Forest $($ mean $=3.92)$ were less motivated by for physical exercise than their counterparts in the Stanislaus (mean= 4.32) and the Deschutes-Willamette National Forests (mean=4.34), $(\mathrm{F}=32.768 ; \mathrm{p}<.001)$.

Lastly, to develop my skills was considered a more important reason to visit the wilderness by respondents in the Stanislaus National Forest $(m e a n=3.71)$ than the Klamath $(\mathrm{mean}=3.50)$ and Deschutes-Willamette National Forests (mean=3.42), $(\mathrm{F}=11.851 ; \mathrm{p}<.001)$.

Table 18: Results of Comparison of Means of Motivations for the Three Regions.

\begin{tabular}{lcccc}
\hline Motivational item & $\begin{array}{c}\text { Deschutes- } \\
\text { Willamette }\end{array}$ & Stanislaus & Klamath & $\mathrm{F}$ \\
\hline To be outdoors & 4.74 & 4.74 & 4.75 & .096 \\
For relaxation & $4.43 \mathrm{a}$ & $4.58 \mathrm{~b}$ & $4.41 \mathrm{a}$ & $12.223^{* * *}$ \\
$\begin{array}{l}\text { To experience natural } \\
\text { surroundings }\end{array}$ & $4.73 \mathrm{~b}$ & $4.76 \mathrm{~b}$ & $4.67 \mathrm{a}$ & $4.260^{*}$ \\
To get away from the regular & $4.54 \mathrm{~b}$ & $4.67 \mathrm{c}$ & $4.44 \mathrm{a}$ & $16.822^{* * *}$ \\
routine & & & & \\
For family recreation & $3.68 \mathrm{~b}$ & $3.85 \mathrm{c}$ & $3.38 \mathrm{a}$ & $15.286^{* * *}$ \\
To be with my friends & $4.00 \mathrm{a}$ & $4.28 \mathrm{~b}$ & $3.90 \mathrm{a}$ & $20.981^{* * *}$ \\
For the challenge or sport & $4.00 \mathrm{~b}$ & $4.14 \mathrm{c}$ & $3.76 \mathrm{a}$ & $16.458^{* * *}$ \\
For physical exercise & $4.34 \mathrm{~b}$ & $4.32 \mathrm{~b}$ & $3.92 \mathrm{a}$ & $32.758^{* * *}$ \\
To develop my skills & $3.43 \mathrm{a}$ & $3.71 \mathrm{~b}$ & $3.50 \mathrm{a}$ & $11.851^{* * *}$ \\
\hline
\end{tabular}

Next, differences in visitor satisfaction between the three regions are described (see Table 19).

Respondents reported higher overall satisfaction with their visit in the Stanislaus $($ mean=2.93) and Klamath National Forests $($ mean= 2.96) than in the Deschutes-Willamette National Forest $($ mean $=2.89),(\mathrm{F}=9.915 ; \mathrm{p}<.001)$.

Satisfaction with the quality of wilderness characteristics such as quiet and solitude was higher for wilderness recreationists in the Stanislaus (mean=4.37) and Klamath National Forests $($ mean $=4.48)$ than in the Deschutes-Willamette National Forests (mean=4.27), $(\mathrm{F}=9.49 ; \mathrm{p}<.001)$. The same trend was apparent for visitors' satisfaction with the wilderness 
experience. Again, respondents in the Stanislaus (mean=4.49) and Klamath National Forests (mean $=4.48)$ were more satisfied than wilderness users in the Deschutes- Willamette National Forests (mean=4.34), $(\mathrm{F}=12.492 ; \mathrm{p}<.001)$.

Lack of human influence was evaluated better by wilderness recreationists in the Stanislaus National Forest (mean=4.02), than in the Deschutes-Willamette $($ mean=3.90) and the Klamath (mean=3.89), $(\mathrm{F}=4.511 ; \mathrm{p}<.05)$. The visitors' assessment of environmental conditions only differed significantly between the Deschutes-Willamette (mean=4.36) and the Stanislaus National Forests (mean=4.45), $(\mathrm{F}=3.151 ; \mathrm{p}<.05)$.

All trip attributes produced significant results. Visitors in the Stanislaus (mean=4.74) and Klamath National Forests (mean=4.72) more strongly agreed that they thoroughly enjoyed their visit to the wilderness than the Oregon portion of the sample (mean=4.64), $(\mathrm{F}=10.271 ; \mathrm{p}<.001)$. The respondents in the Deschutes-Willamette (mean=4.65) and Klamath National Forests (mean=4.64) indicated a slightly lower level of agreement than the visitors in the Stanislaus National Forest (mean=4.73) when asked if the wilderness visit was well worth the money spent, $(\mathrm{F}=5.297 ; \mathrm{p}<.001)$. The same pattern was noted for this wilderness and its surroundings are in good condition. Visitors in the Deschutes-Willamette $($ mean=4.22) and the Klamath National Forests (mean=4.19) agreed less with this statement than the recreationists in the Stanislaus National Forest (mean=4.46), $(\mathrm{F}=28.931 ; \mathrm{p}<.001)$.

While some visitors disagreed that they were disappointed with some aspects of their visit, the respondents in the Deschutes-Willamette National Forests (mean=1.81) expressed a significantly stronger disagreement with that statement than the ones in the Klamath National Forest (mean=1.98), $(\mathrm{F}=3.980 ; \mathrm{p}<.05)$. 
Table 19: Results of Comparison of Means of Overall Satisfaction, Satisfaction with Quality Attributes, and Level of Agreement with Trip Attributes for the Three Regions.

\begin{tabular}{|c|c|c|c|c|}
\hline & $\begin{array}{l}\text { Deschutes- } \\
\text { Willamette }\end{array}$ & Stanislaus & Klamath & $\mathrm{F}$ \\
\hline Overall satisfaction recoded & $2.89 a$ & $2.93 b$ & $2.96 b$ & $9.915 * * *$ \\
\hline \multicolumn{5}{|l|}{ Quality Attributes } \\
\hline Quiet or solitude & $4.27 \mathrm{a}$ & $4.37 b$ & $4.48 b$ & $9.449 * * *$ \\
\hline Lack of human influence & $3.90 \mathrm{a}$ & $4.02 \mathrm{~b}$ & $3.89 \mathrm{a}$ & $4.511^{*}$ \\
\hline Wilderness experience & $4.34 \mathrm{a}$ & $4.49 b$ & $4.48 b$ & $12.492 * * *$ \\
\hline Environmental conditions & $4.36 \mathrm{a}$ & $4.45 b$ & $4.37 \mathrm{ab}$ & $3.151^{*}$ \\
\hline \multicolumn{5}{|l|}{ Trip Attributes } \\
\hline $\begin{array}{l}\text { I thoroughly enjoyed my visit to this } \\
\text { wilderness. }\end{array}$ & $4.64 a$ & $4.74 b$ & $4.72 b$ & $10.271 * * *$ \\
\hline $\begin{array}{l}\text { My trip to this wilderness was well } \\
\text { worth the money I spent to take it. }\end{array}$ & $4.65 a$ & $4.73 b$ & $4.64 a$ & $5.297 * *$ \\
\hline $\begin{array}{l}\text { I was disappointed with some aspects } \\
\text { of my visit to this wilderness. }\end{array}$ & $1.81 \mathrm{a}$ & $1.90 \mathrm{ab}$ & $1.98 \mathrm{~b}$ & $3.980 *$ \\
\hline $\begin{array}{l}\text { This wilderness and its surroundings } \\
\text { are in good condition. }\end{array}$ & $4.22 \mathrm{a}$ & $4.46 \mathrm{~b}$ & $4.19 \mathrm{a}$ & $28.931 * * *$ \\
\hline
\end{tabular}

In addition to the satisfaction measures, differences in perceived crowding levels were investigated (see Table 20). Visitors did not feel crowded at all in the wilderness areas in all three regions. However, wilderness recreationists in the Klamath National Forest (mean=2.04) still felt significantly less crowded than respondents in the Stanislaus $($ mean=2.23) and Deschutes-Willamette National Forests (mean=2.34), $(\mathrm{F}=5.700 ; \mathrm{p}<.01)$.

Table 20: Results of Comparison of Means of Perceived Crowding for the Three Regions.

\begin{tabular}{lcccc}
\hline & $\begin{array}{l}\text { Deschutes- } \\
\text { Willamette }\end{array}$ & Stanislaus & Klamath & F \\
\hline $\begin{array}{l}\text { How crowded did you feel } \\
\text { during this visit? }\end{array}$ & $2.34 \mathrm{~b}$ & $2.23 \mathrm{~b}$ & $2.04 \mathrm{a}$ & $5.700^{* * *}$ \\
\hline
\end{tabular}

\section{$R Q$ 6: Are there significant differences in trip characteristics, motivations, satisfaction, crowding and conflict between female and male visitors?}

Independent samples t-tests and Pearson's Chi-square tests were utilized for analyzing differences between female and male visitors across all wilderness areas. Table 21 shows the results of the cross tabulations for overnight and day use for female and male visitors. A 
higher percentages of women $(57.5 \%)$ than of men were recreating in the wilderness for a day only. Moreover, less females (42.5\%) than males (54.7\%) were on an overnight trip, $\left(X^{2}=32.710 ; \mathrm{df}=1 ; \mathrm{p}<.001\right)$.

Table 21: Results of Cross Tabulations for Overnight and Day Use for Female and Male Visitors.

\begin{tabular}{lccc}
\hline & Female & Male & \\
\hline Day trip & 57.5 & 45.3 & $X^{2}=32.710$ \\
Overnight trip & 42.5 & 54.7 & $\mathrm{df}=1$ \\
& & & $\mathrm{p}<.001$ \\
\hline
\end{tabular}

These trends regarding trip type were amplified by the results of the comparison of means for the duration of the stay (see Table 22). Men spent more time in the wilderness than women. This was found for both overnight and day use. Male visitors recreated for more days $($ mean $=2.62)$ than female visitors (mean=1.61) when on an overnight trip, $(t=5.6964$; $\mathrm{p}<.001)$. Males tended to spend more hours $($ mean=4.85) in wilderness than their female counterparts $($ mean $=4.32)$ when on a day trip, $(\mathrm{t}=3.950 ; \mathrm{p}<.001)$.

Although females visited in slightly larger groups $($ mean=3.90) than males (mean=3.66) these differences were not significant. There were no differences in the number of children ( $\mathrm{t}=-.806 ; \mathrm{p}>.05)$ and the number of vehicles per group for the two user groups, $(\mathrm{t}=-.375 ; \mathrm{p}>.05)$.

Table 22: Results of Comparison of Means of Trip Length and Group Characteristics for Female and Male Visitors.

\begin{tabular}{lccl}
\hline & Female & Male & T \\
\hline Days in Wilderness & 1.61 & 2.62 & $5.6964 * *$ \\
Hours in Wilderness & 4.32 & 4.85 & $3.950^{* * *}$ \\
Group size & 3.90 & 3.66 & -1.628 \\
Children in group & 2.21 & 1.95 & -.806 \\
Number of vehicles per group & 1.39 & 1.37 & -.375 \\
\hline
\end{tabular}


Next, reasons to visit the wilderness were analyzed by gender. On average, both female and male recreationists rated all nine motivational items on the list as very important or extremely important.

The analysis of differences in motivations based on gender revealed that female visitors rated each of the nine items as more important than male respondents (see Table 23). For seven out of the nine items those differences in average importance rating were statistically significant.

Female respondents placed a significantly higher level of importance on to be outdoors $($ mean $=4.79)$ than the males $($ mean $=4.72),(\mathrm{t}=-3.667 ; \mathrm{p}<.001)$. To experience natural surroundings was a slightly more important motivational factor for the female users $(\mathrm{mean}=4.77)$ that for males $($ mean $=4.72),(\mathrm{t}=-2.202 ; \mathrm{p}<.05)$. Women indicated for relaxation $($ mean $=4.57)$ as a more important reason to visit wilderness than men $($ mean $=4.45),(\mathrm{t}=-$ 4.047; $\mathrm{p}<.05)$. Male visitors were less likely to be motivated by to get away from the regular routine $($ mean $=4.54)$ than female visitors $($ mean $=4.64),(\mathrm{t}=-3.473 ; \mathrm{p}<.001)$. The same was true for the two items that are based on social motivations; male recreationists reported lower importance ratings for for family recreation $($ mean $=3.61)$ than females $($ mean $=3.88),(\mathrm{t}=-$ 4.519, $\mathrm{p}<.001)$. Also, to be with my friends was less important for men (mean=4.03) than for women $($ mean $=4.22),(\mathrm{t}=.3 .6333 ; \mathrm{p}<.001)$. Finally, for physical exercise was rated lower on the importance scale by male respondents $($ mean $=4.21)$ than by female respondents $(\mathrm{mean}=4.40),(\mathrm{t}=-4.992 ; \mathrm{p}<.001)$.

The only two motivational items that were not rated significantly different by male and female visitors were for the challenge or sport (mean females $=4.06$, mean males $=4.00$; $\mathrm{t}=-1.398 ; \mathrm{p}>.05)$ and to develop my skills (mean females= 3.57, mean males $=3.54 ; \mathrm{t}=-.525$; $\mathrm{p}>.05)$. 
Table 23: Results of Comparison of Means of Motivations for Male and Female Visitors.

\begin{tabular}{lccl}
\hline Motivational item & Female & Male & \multicolumn{1}{c}{$\mathrm{T}$} \\
\hline To be outdoors & 4.79 & 4.72 & $-3.667^{* * *}$ \\
To experience natural surroundings & 4.77 & 4.72 & $-2.202^{*}$ \\
For relaxation & 4.57 & 4.45 & $-4.047^{* * *}$ \\
To get away from the regular routine & 4.64 & 4.54 & $-3.473^{* * *}$ \\
For family recreation & 3.88 & 3.61 & $-4.519^{* * *}$ \\
To be with my friends & 4.22 & 4.03 & $-3.6333^{* * *}$ \\
For the challenge or sport & 4.06 & 4.00 & -1.398 \\
For physical exercise & 4.40 & 4.21 & $-4.992^{* * *}$ \\
To develop my skills & 3.57 & 3.54 & -.525 \\
\hline
\end{tabular}

In addition to motivational factors for wilderness recreation, differences in the most important reason to visit was examined. As shown in Table 24, very few respondents in either group mentioned the proximity of the wilderness to their home as the primary reason to visit. Male visitors reported to recreate in the wilderness because they enjoy the place itself more often than female visitors. Women were more likely to name it is a good place for the outdoor activities I enjoy than men. However, none of these differences were significant $\left(X^{2}=3.957 ; \mathrm{df}=3 ; \mathrm{p}>.05\right)$.

Table 24: Results of Comparison of Cross Tabulations for Primary Reason to Visit for Female and Male Visitors.

\begin{tabular}{lccc}
\hline Primary Reason to Visit & Female & Male & \\
\hline I enjoy the place itself & 36.6 & 39.3 & $X^{2}=3.957$ \\
$\begin{array}{l}\text { It is a good place for the outdoor activities } \\
\text { I enjoy }\end{array}$ & 41.1 & 37.2 & $\begin{array}{c}\mathrm{df}=3 \\
\text { I wanted to spend more time with my } \\
\text { companions }\end{array}$ \\
\begin{tabular}{l} 
It was close to home \\
\hline
\end{tabular} & 16.6 & 18.1 & \\
\hline
\end{tabular}

The independent samples t-test revealed few differences in trip satisfaction between male and female respondents (see Table 25). The average overall satisfaction ratings were identical for both user groups (mean=2.91). 
Although female visitors indicated higher satisfaction with all four quality attributes, lack of human influence was the only attribute that females (mean=4.02) were significantly more satisfied with than males (mean $=3.90),(\mathrm{t}=-2.947 ; \mathrm{p}<.01)$.

Female visitors were more likely to agree they thoroughly enjoyed their visit to the wilderness $($ mean $=4.73)$ in comparison to male recreationists $($ mean $=4.67),(t=-2.645, \mathrm{p}<.01)$ Significant values were also found for the level of agreement with the statement this wilderness and its surroundings are in good condition. Women more strongly agreed (mean= $4.35)$ with this statement than men $($ mean $=4.28),(\mathrm{t}=-2.012, \mathrm{p}<.05)$.

Female recreationists indicated higher agreement when asked if the trip was worth the money they spent on taking it $($ mean $=4.71)$ than male recreationists $($ mean $=4.66),(t=-1.926$, p>.05). Also, female respondents reported slightly stronger disagreement for being disappointed with some aspects of their trip (mean=1.82) than males (mean=1.89), $(\mathrm{t}=1,660$, p>.05). Despite the analysis revealing small differences between the two groups for these last two statements, those differences were not significant.

Table 25: Results of Comparison of Means of Overall Satisfaction, Satisfaction with Quality Attributes, and Level of Agreement with Trip Attributes for Female and Male Visitors.

\begin{tabular}{lccc}
\hline & Female & Male & \multicolumn{1}{c}{ T } \\
\hline $\begin{array}{l}\text { Overall satisfaction recoded } \\
\text { Quality Attributes }\end{array}$ & 2.91 & 2.91 & .244 \\
$\quad$ & 4.36 & 4.33 & -1.049 \\
$\quad$ Quiet or solitude & 4.02 & 3.90 & $-2.947^{* *}$ \\
$\quad$ Lack of human influence & 4.45 & 4.40 & -1.731 \\
$\quad$ Wilderness experience & 4.43 & 4.38 & -1.297 \\
$\quad$ Environmental conditions & & & \\
$\begin{array}{l}\text { Trip Attributes } \\
\text { I thoroughly enjoyed my visit to this wilderness. }\end{array}$ & 4.73 & 4.67 & $-2.645^{* *}$ \\
$\quad \begin{array}{l}\text { My trip to this wilderness was well worth the money I } \\
\text { spent to take it. }\end{array}$ & 4.71 & 4.66 & -1.926 \\
$\begin{array}{l}\text { I was disappointed with some aspects of my visit to this } \\
\text { wilderness. }\end{array}$ & 1.82 & 1.89 & 1.660 \\
$\quad$ This wilderness and its surroundings are in good condition. & 4.35 & 4.28 & $-2.012^{*}$ \\
\hline
\end{tabular}


Next, expected and perceived crowding levels between the two user groups were examined (see Table 26).

The analysis produced significant results for expected crowding, $\left(X^{2}=13.906 ; \mathrm{df}=5\right.$; $\mathrm{p}<.05)$. A little more than a quarter of female $(28.2 \%)$ and male visitors $(27.6 \%)$ reported that they experienced less crowding than expected. Slightly more male respondents $(46.0 \%)$ than females (44.9\%) indicated they saw about as many people as they expected. Male visitors $(23.1 \%)$ were more likely to report that they saw more people than expected compared to female visitors (20.8\%). The proportion of women (6.0\%) stating they didn't have any crowding expectations was almost twice as large as the proportion of men (3.3\%) who said they did not have any expectations.

No significant differences were found for the perceived crowding levels for male and female respondents.

Table 26: Results of Cross Tabulation for Expected and Perceived Crowding for Female and Male Visitors.

\begin{tabular}{lccc}
\hline & Female & Male & \\
\hline How did the number of people you saw & & & $X^{2}=13.906$ \\
compare with what you expected to see? & & & $\mathrm{df}$ \\
$\quad$ A lot less than you expected & 13.3 & 11.4 & $\mathrm{p}<.05$ \\
A little less than you expected & 14.9 & 16.2 & \\
About what you expected & 44.9 & 46.0 & \\
A little more than you expected & 14.2 & 15.2 & \\
A lot more than you expected & 6.6 & 7.9 & \\
You didn't have any expectations & 6.0 & 3.3 & \\
How crowded did you feel during this visit? & & & $X^{2}=5.422$ \\
Not at all crowded & 70.5 & 66.0 & $\mathrm{df}=3$ \\
Slightly crowded & 20.1 & 23.9 & $\mathrm{p}>.05$ \\
Moderately crowded & 9.0 & 9.6 & \\
Extremely crowded & $<1.0$ & $<1.0$ & \\
\hline
\end{tabular}

In order to gain a deeper understanding of gender- based differences in perceived crowding, actual crowding, and preferred crowding, the level of agreement with a number of 
crowding attributes were tested by gender. The independent samples t- test produced no significant results for actual and preferred crowding levels (see Table 27). Female respondents reported only a slightly higher percentage of time they were in sight of other visitors $($ mean $=16.74)$ than male respondents $($ mean $=16.40),(t=-.414 ; \mathrm{p}>.05)$. The same was found for acceptable percentages of time in sight of other groups for female (mean=22.93) and male visitors $($ mean $=21.55),(\mathrm{t}=-1.785 ; \mathrm{p}>.05)$.

The number of group encounters did not significantly vary between women $($ mean=5.18) and men $($ mean=5.66), $(t=1.494, \mathrm{p}>.05)$, neither did the acceptable number of group encounters. The average acceptable number of group encounters (mean=5.41) was lower than the actual number of group encounters for male respondents and higher for female recreationists $($ mean $=6.00)$.

Table 27: Results of Comparison of Means of Actual and Preferred Crowding for Female and Male Visitors.

\begin{tabular}{lccc}
\hline & Female & Male & T \\
\hline Percent of time in sight of other groups & 16.74 & 16.40 & -.414 \\
Acceptable percentage of time in sight of & 22.93 & 21.55 & -1.785 \\
other groups & & & \\
Number of group encounters & 5.18 & 5.66 & 1.494 \\
Acceptable number of group encounters & 6.00 & 5.41 & -1.428 \\
\hline
\end{tabular}

The analysis of the level of agreement with crowding and conflict attributes included some significant values. Of the six attributes, four were evaluated significantly different by the two groups (see Table 28).

Female visitors showed stronger agreement with the statement I had the opportunity to recreate without feeling crowded $($ mean $=4.54)$ than male visitors (mean=4.47), $(\mathrm{t}=-2.465$; $\mathrm{p}<.05)$. Female respondents also reported slightly higher agreement (mean=4.62) than males (mean $=4.54)$ with regards to finding places to recreate without conflict from other visitors, $(\mathrm{t}=-3.004 ; \mathrm{p}<.01)$. Even though both groups disagreed that they avoided some places in the 
wilderness because there were too many people there, female recreationists scored lower $($ mean $=2.00)$ than males $($ mean $=2.13)$ for this statement, $(\mathrm{t}=2.482 ; \mathrm{p}<.05)$. The number of people at this wilderness reduced my enjoyment also achieved lower scores from women $($ mean $=1.83)$ than from men $($ mean $=1.92),(\mathrm{t}=2.577 ; \mathrm{p}<.01)$.

There were no significant values produced for the last two statements on the list. Both female (mean=1.73) and male interviewees (mean=1.78) disagreed that the behavior of other wilderness recreationists interfered with the quality of their experience, $(t=1.179 ; p>.05)$. Neither agreement nor disagreement for the statement the other people at this wilderness increased my enjoyment was indicated by both female (mean=3.01) and male visitors $($ mean=2.92), $(\mathrm{t}=-1.842 ; \mathrm{p}>.05)$.

Table 28: Results of Comparison of Means of Level of Agreement with Crowding and Conflict Attributes for Male and Female Visitors.

\begin{tabular}{lccc}
\hline Attribute & Female & Male & T \\
\hline $\begin{array}{l}\text { I had the opportunity to recreate without } \\
\text { feeling crowded. }\end{array}$ & 4.54 & 4.47 & $-2.465^{*}$ \\
$\begin{array}{l}\text { I could find places to recreate without } \\
\text { conflict from other visitors. }\end{array}$ & 4.62 & 4.54 & $-3.004^{* *}$ \\
$\begin{array}{l}\text { I avoided some places at this wilderness } \\
\text { because there were too many people there. }\end{array}$ & 2.00 & 2.13 & $2.482^{*}$ \\
$\begin{array}{l}\text { The number of people at this wilderness } \\
\text { reduced my enjoyment. }\end{array}$ & 1.83 & 1.92 & $2.577^{* *}$ \\
$\begin{array}{l}\text { The behavior of other people at this } \\
\text { wilderness interfered with the quality of } \\
\text { my experience. }\end{array}$ & 1.73 & 1.78 & 1.179 \\
$\begin{array}{l}\text { The other people at this wilderness } \\
\text { increased my enjoyment. }\end{array}$ & 3.01 & 2.92 & -1.842 \\
\hline
\end{tabular}

Then, preferred group sizes for the two user groups were compared (see Table 29). The cross tabulation produced significant values $\left(X^{2}=9.065 ; \mathrm{df}=3 ; \mathrm{p}<.05\right)$. The vast majority of both gender based groups preferred wilderness recreation in small groups (82.0\%). Slightly more men $(13.1 \%)$ than women $(11.5 \%)$ preferred groups of six to fifteen people. Very few female $(1.6 \%)$ and male visitors $(<1.0 \%)$ said they favored large groups. Less than five 
percent of both male and female respondents indicated that the group size makes no difference to them.

Table 29: Results for Cross Tabulations for Preferred Group Size for Female and Male Visitors.

\begin{tabular}{lccc}
\hline Group size & Female & Male & \\
\hline Small (5 people or less) & 82.0 & 82.0 & $X^{2}=9.065$ \\
Medium (6-15 people) & 11.5 & 13.1 & $\mathrm{df}=3$ \\
Large (16 - 25 people) & 1.6 & $<1$ & $\mathrm{p}<.05$ \\
Makes no difference to me & 4.9 & 4.5 & \\
\hline
\end{tabular}

Last, potential differences between female and male respondents in experiencing social conflict during their visit were analyzed (see Table 30). It was found that equal portions of each user group reported conflict with other parties $\left(X^{2}=.001 ; \mathrm{df}=1 ; \mathrm{p}>.05\right)$.

Table 30: Results of Cross Tabulation for Social Conflict for Female and Male Visitors.

\begin{tabular}{lccc}
\hline & Female & Male \\
\hline Did you have any conflict with other parties? & & & $X^{2}=.001$ \\
Yes & 2.2 & 2.2 & $\mathrm{df}=1$ \\
No & 97.8 & 97.8 & $\mathrm{p}>.05$ \\
\hline
\end{tabular}

RQ 6a: Can a typology be derived from variables such as motivations, satisfaction levels, perceived crowding and trip type for female and male visitors?

In order to potentially derive typologies for male and female visitors, the proportions of each gender- based group were calculated for each region (see Table 31). There was a larger share of female visitors $(38.90 \%)$ in the wilderness areas in the Oregon National Forests than in the other two regions. Male recreationists accounted for more than two thirds of the sample in the wilderness areas in the Klamath National Forest and in the Stanislaus National Forest. 
Table 31: Proportions Female and Male Visitors per Region.

\begin{tabular}{lcccc}
\hline & \multicolumn{2}{c}{ Female } & \multicolumn{2}{c}{ Male } \\
& Frequencies & Valid Percentage & Frequencies & Valid Percentage \\
\hline $\begin{array}{l}\text { Deschutes and } \\
\text { Willamette National }\end{array}$ & 460 & 38.90 & 723 & 61.10 \\
$\begin{array}{l}\text { Forest } \\
\text { Klamath National }\end{array}$ & 132 & 34.10 & 255 & 65.90 \\
$\begin{array}{l}\text { Forest } \\
\text { Stanislaus National } \\
\text { Forest }\end{array}$ & 232 & 25.20 & 690 & 74.80 \\
\hline
\end{tabular}

Independent samples t-tests were conducted examining differences in motivations between male and female visitors for each of the three regions individually (see Tables 32$34)$.

For the wilderness areas in the Deschutes-Willamette National Forests female respondents rated all motivational items as more important than male respondents. Eight out of the nine motivational items were rated significantly different between male and female visitors (see Table 32).

Female visitors placed more emphasis on to be outdoors as a motivational factor for their wilderness visit $($ mean $=4.83)$ than male visitors $($ mean $=4.68),(t=-5.192, \mathrm{p}<.001)$. To experience natural surroundings also was more relevant to women $($ mean $=4.79)$ than to men $($ mean $=4.70),(\mathrm{t}=-3.105, \mathrm{p}<.01)$. For relaxation was a significantly more important reason to recreate in the wilderness for the female proportion of the sample (mean=4.58) than it was for the male proportion $($ mean $=4.35),(\mathrm{t}=-5.161, \mathrm{p}<.001)$. Highly significant results were found for to get away from the regular routine, which achieved lower importance scores by men $($ mean $=4.46)$ than by women $($ mean $=4.67),(t=-5.184, \mathrm{p}<.001)$.

The two social motivational items also produced significant values. Females rated for family recreation as more important $($ mean $=3.95)$ than males $($ mean $=3.52),(\mathrm{t}=-5.461$; 
$\mathrm{p}<.001)$. Females were also more likely to be motivated by to be with my friends $($ mean $=4.19)$ than males $($ mean $=3.89),(\mathrm{t}=-4.514 ; \mathrm{p}<.001)$.

For the challenge or sport yielded higher importance scores from female respondents $(\mathrm{mean}=4.10)$ than from male respondents $($ mean $=3.94),(\mathrm{t}==-2.510 ; \mathrm{p}<.05)$. Furthermore, for physical exercise played a more important role as a motivational factor for women (mean= 4.51) than it did for men (mean=4.24), $(\mathrm{t}=-5.799 ; \mathrm{p}<.001)$.

The only motivational items that was not rated significantly different by female $($ mean $=3.48)$ and male wilderness recreationists $($ mean=3.41) in this region was to develop my skills, $(\mathrm{t}=-.831 ; \mathrm{p}>.05)$.

Table 32: Results of Comparison of Means of Motivations for Female and Male Visitors in the Deschutes and Willamette National Forests.

\begin{tabular}{lccl}
\hline Motivational item & Female & Male & \multicolumn{1}{c}{$\mathrm{T}$} \\
\hline To be outdoors & 4.83 & 4.68 & $-5.192^{* * *}$ \\
To experience natural surroundings & 4.79 & 4.70 & $-3.105^{* *}$ \\
For relaxation & 4.58 & 4.35 & $-5.161^{* * *}$ \\
To get away from the regular routine & 4.67 & 4.46 & $-5.184^{* * *}$ \\
For family recreation & 3.95 & 3.52 & $-5.461^{* * *}$ \\
To be with my friends & 4.19 & 3.89 & $-4.514^{* * *}$ \\
For the challenge or sport & 4.10 & 3.94 & $-2.510^{*}$ \\
For physical exercise & 4.51 & 4.24 & $-5.799^{* * *}$ \\
To develop my skills & 3.48 & 3.41 & -.831 \\
\hline
\end{tabular}

Then, the same analysis was executed for the wilderness areas in the Stanislaus National Forest. Even though female respondents rated all motivational items higher or at least the same as male respondents, there was only one instance where those differences were statistically significant (see Table 33).

To be outdoors was almost equally important for both women $($ mean=4.75) and men $($ mean $=4.74)$ as a motivation to recreate in the two wilderness areas, $(\mathrm{t}=-.231 ; \mathrm{p}>.05)$. 
Both user groups placed identical importance on experiencing natural surroundings as a motivational factor $($ mean=4.76), $(\mathrm{t}=.026 ; \mathrm{p}>.05)$. All other items but one were rated as slightly more important by the female part of the sample.

The only item that was rated significantly different by women (mean=4.45) and men (mean=4.27) in the wilderness areas in the Stanislaus National Forest was for physical exercise, $(\mathrm{t}=-2.674 ; \mathrm{p}<.01)$.

Table 33: Results of Comparison of Means of Motivations for Female and Male Visitors in the Stanislaus National Forest.

\begin{tabular}{lccl}
\hline Motivational item & Female & Male & T \\
\hline To be outdoors & 4.75 & 4.74 & -.231 \\
To experience natural surroundings & 4.76 & 4.76 & .026 \\
For relaxation & 4.63 & 4.57 & -1.285 \\
To get away from the regular routine & 4.71 & 4.65 & -1.172 \\
For family recreation & 3.90 & 3.82 & -.701 \\
To be with my friends & 4.39 & 4.25 & -1.745 \\
For the challenge or sport & 4.21 & 4.11 & -1.225 \\
For physical exercise & 4.45 & 4.27 & $-2.674^{* *}$ \\
To develop my skills & 3.73 & 3.70 & -.296 \\
\hline
\end{tabular}

Last, the motivations for wilderness recreation for the two groups were compared for the areas in the Klamath National Forest (see Table 34). In contrast to the analysis for the Stanislaus and Deschutes-Willamette National Forests, male respondents rated to get away from the regular routine, for the challenge or sport, and for physical exercise as slightly more important than their female counterparts. However, none of the values for the gender-based comparison for this region were statistically significant. 
Table 34: Results of Comparison of Means of Motivations for Female and Male Visitors in the Klamath National Forest.

\begin{tabular}{lccc}
\hline Motivational item & Female & Male & T \\
\hline To be outdoors & 4.76 & 4.76 & .069 \\
To experience natural surroundings & 4.70 & 4.66 & -.573 \\
For relaxation & 4.45 & 4.40 & -.513 \\
To get away from the regular routine & 4.43 & 4.45 & .237 \\
For family recreation & 3.59 & 3.28 & -1.799 \\
To be with my friends & 3.98 & 3.86 & -.798 \\
For the challenge or sport & 3.65 & 3.84 & 1.361 \\
For physical exercise & 3.91 & 3.94 & .282 \\
To develop my skills & 3.59 & 3.45 & -1.004 \\
\hline
\end{tabular}

Next, means for all satisfaction, crowding, and conflict variables, which produced significant results in the analysis in research question 6, were compared for male and female visitors in the individual regions. Table 35 displays the results of this comparison for the wilderness areas in the Deschutes- and Willamette National Forests.

Men spent significantly more time in wilderness $($ mean $=1.42)$ than women $($ mean= .86) when on an overnight trip, $(\mathrm{t}=3.245, \mathrm{p}<.01)$. The same was true for day trips; male visitors recreated for more hours $($ mean $=4.91)$ than their female counterparts $($ mean=4.34), $(\mathrm{t}=3.088, \mathrm{p}<.01)$

The three satisfaction attributes that produced significant results in research question 6 were also significant in the wilderness areas in the Deschutes and Willamette National Forests. Both user groups rated lack of human influence as very good, but the average rating by females $($ mean $=4.00)$ was still higher than by males $($ mean $=3.83),(\mathrm{t}=-2.835, \mathrm{p}<.01)$. Female respondents more strongly agreed that they thoroughly enjoyed their visit to the wilderness $($ mean $=4.69)$ than males $($ mean $=4.60),(t=-2.620, p<.01)$. Female interviewees also demonstrated a stronger level of agreement with the statement this wilderness and its surroundings are in good condition $($ mean $=4.30)$ compared to males (mean=4.16), $(\mathrm{t}=-$ $2.776, \mathrm{p}<.01)$. 
Two of the overall significant crowding and conflict items were significant for the Oregon wilderness areas. A higher proportion of women strongly agreed that they had the opportunity without feeling crowded $($ mean $=4.59)$ in comparison to men $($ mean=4.49), $(\mathrm{t}=-$ $1.982, \mathrm{p}<.05)$. Males less strongly disagreed (mean=2.04) with the statement the other people at this wilderness increased my enjoyment than females (mean=1.87), $(\mathrm{t}=-2.074)$.

Table 35: Results of Comparison of Means of Selected Variables for Female and Male Visitors in the Deschutes and Willamette National Forests.

\begin{tabular}{lccc}
\hline Trip Characteristics, Crowding and Conflict Attributes & Female & Male & T \\
\hline Days in Wilderness & .86 & 1.42 & $3.245^{* *}$ \\
Hours in Wilderness & 4.34 & 4.91 & $3.088^{* *}$ \\
Satisfaction Attributes & & & \\
Lack of Human Influence & 4.00 & 3.83 & $-2.835^{* *}$ \\
I thoroughly enjoyed my visit to this wilderness. & 4.69 & 4.60 & $-2.620^{* *}$ \\
This wilderness and its surroundings are in good condition. & 4.30 & 4.16 & $-2.776^{* *}$ \\
$\begin{array}{l}\text { I had the opportunity to recreate without feeling crowded } \\
\text { I could find places to recreate without conflict from other }\end{array}$ & 4.52 & 4.43 & $-1.982^{*}$ \\
$\begin{array}{l}\text { visitors. } \\
\text { I avoided some places at this wilderness because there }\end{array}$ & 4.59 & 4.49 & -2.605 \\
$\begin{array}{l}\text { were too many people there. } \\
\text { The other people at this wilderness increased my }\end{array}$ & 2.07 & 2.19 & .100 \\
enjoyment. & 1.87 & 2.04 & $-2.074^{*}$ \\
\hline
\end{tabular}

Only three of the tested variables produced significant results for the comparison between the two user groups in the Stanislaus National Forest (see Table 36).

Women indicated that they more thoroughly enjoyed their visit to this wilderness $($ mean $=4.80)$ than men $($ mean $=4.72),(\mathrm{t}=-2.061, \mathrm{p}<.05)$. Female visitors more strongly disagreed $($ mean $=1.84)$ than male visitors $($ mean $=2.04)$ that they avoided some places at the wilderness because there were too many people there, $(\mathrm{t}=2.525, \mathrm{p}<.05)$. 
Table 36: Results of Comparison of Means of Selected Variables for Female and Male Visitors in the Stanislaus National Forests.

\begin{tabular}{lccc}
\hline Trip Characteristics, Crowding and Conflict Attributes & Female & Male & T \\
\hline Days in Wilderness & 3.31 & 3.79 & 1.462 \\
$\begin{array}{l}\text { Hours in Wilderness } \\
\text { Satisfaction Attributes }\end{array}$ & 4.34 & 4.62 & 1.359 \\
$\begin{array}{l}\text { Lack of Human Influence } \\
\text { I thoroughly enjoyed my visit to this wilderness. }\end{array}$ & 4.07 & 4.00 & -.985 \\
$\begin{array}{l}\text { This wilderness and its surroundings are in good } \\
\text { condition. }\end{array}$ & 4.80 & 4.72 & $-2.061^{*}$ \\
$\begin{array}{l}\text { I had the opportunity to recreate without feeling } \\
\text { crowded }\end{array}$ & 4.57 & 4.45 & -.872 \\
$\begin{array}{l}\text { I could find places to recreate without conflict from } \\
\text { other visitors. }\end{array}$ & 4.69 & 4.62 & -1.340 \\
$\begin{array}{l}\text { I avoided some places at this wilderness because there } \\
\text { were too many people there. }\end{array}$ & 1.84 & 2.04 & $2.525^{*}$ \\
$\begin{array}{l}\text { The other people at this wilderness increased my } \\
\text { enjoyment. }\end{array}$ & 2.86 & 2.92 & .623 \\
\hline
\end{tabular}

Three of the trip characteristics, crowding, and conflict variables were significant for the comparison between male and female wilderness visitors in the Klamath National Forests (see Table 37). Female respondents $($ mean $=4.06)$ spent less hours in the wilderness when on a day trip compared to males $($ mean $=5.53),(t=2.516, \mathrm{p}<.05)$.

I had the opportunity to recreate without feeling crowded triggered stronger agreement with female visitors $($ mean $=4.59)$ than with males $($ mean=4.40), $(\mathrm{t}=-2.569$, $\mathrm{p}<.05)$. Compared to male visitors (mean=4.46) female visitors more strongly agreed (mean=4.62) that they had the opportunity to recreate without conflict from other visitors $(\mathrm{t}=$ $-2.285, \mathrm{p}<.05)$. 
Table 37: Results of Comparison of Means of Selected Variables for Female and Male Visitors in the Klamath National Forests.

\begin{tabular}{|c|c|c|c|}
\hline Trip Characteristics, Crowding and Conflict Attributes & Female & Male & $\mathrm{T}$ \\
\hline Days in Wilderness & 3.33 & 4.63 & 1.158 \\
\hline Hours in Wilderness & 4.06 & 5.53 & $2.516^{*}$ \\
\hline \multicolumn{4}{|l|}{ Satisfaction Attributes } \\
\hline Lack of Human Influence & 4.02 & 3.84 & -1.789 \\
\hline I thoroughly enjoyed my visit to this wilderness. & 4.74 & 4.71 & -.567 \\
\hline $\begin{array}{l}\text { This wilderness and its surroundings are in good } \\
\text { condition. }\end{array}$ & 4.25 & 4.16 & -1.080 \\
\hline $\begin{array}{l}\text { I had the opportunity to recreate without feeling } \\
\text { crowded }\end{array}$ & 4.59 & 4.40 & $-2.569 *$ \\
\hline $\begin{array}{l}\text { I could find places to recreate without conflict from } \\
\text { other visitors. }\end{array}$ & 4.62 & 4.46 & $-2.285^{*}$ \\
\hline $\begin{array}{l}\text { I avoided some places at this wilderness because there } \\
\text { were too many people there. }\end{array}$ & 2.06 & 2.19 & 1.032 \\
\hline $\begin{array}{l}\text { The other people at this wilderness increased my } \\
\text { enjoyment. }\end{array}$ & 3.25 & 3.01 & -1.952 \\
\hline
\end{tabular}




\section{CHAPTER 5- DISCUSSION AND CONCLUSIONS}

In the final chapter of this thesis the results for each research questions are summarized and discussed. Based on findings from this study, implications for wilderness management as well as recommendations for future research are proposed. Last, conclusions are drawn.

\section{RQ1: What does the sample of visitors look like across the wilderness areas?}

The majority of recreationists in the wilderness area studied in this thesis were highly educated, white males with considerable household income. More than two thirds of the visitors $(69.0 \%)$ held a Bachelor's degree or higher. There was a wide age range with a focus on the medium age categories and with few visitors over 70 and under 20 years of age. Hardly any visitors were of Hispanic, Latino, or Spanish origin (1.4\%) and almost the entire sample (98.6\%) described themselves as White.

Most respondents indicated a substantial annual household income of $\$ 50 \mathrm{k}-150 \mathrm{k}$ $(54.6 \%)$. These visitor characteristics are in accordance to what previous wilderness recreation studies have found (Stankey, 1980; Lucas, 1980; Cole, 2001).

As expected, male visitors (66.9\%) made up a larger portion of the sample than female visitors (33.1\%). Even though females still are a minority group, the portion of this user group as represented in this thesis is similar to what other recent wilderness studies have revealed (Cole \& Hall, 2008). The percentage proved to be larger than gender-based user segments reported in early studies (Stankey, 1980; Lucas, 1980). This is not surprising. In the past decades societal changes with regards to traditional gender roles have led to more and more women entering traditionally male dominated fields, ranging from working in engineering jobs to participation in adventurous outdoor recreation activities (Roggenbuck \& Watson, 1989; Dougherty et al., 2005). 
Day users and overnight users accounted for approximately $50 \%$ of the sample each. Overnight users spent an average of 2.28 days in the wilderness, whereas day users recreated for 4.64 hours on average. Respondents recreated in small groups of 3.20 persons on average. Whereas small groups are typical for wilderness recreation, this sample includes an unusually high percentage of overnight users compared to other studies (Papenfuse et al., 2000; Cole 2001; Cole \& Hall, 2008). Interestingly, the wilderness areas in the Californian National Forests account for this high proportion of overnight users. More than half of the wilderness users in the Stanislaus National Forest and a little over $70 \%$ of the ones in the Klamath National Forest were on an overnight trip. For the wilderness areas in the Deschutes and Willamette National Forests the day use and overnight proportion were more similar to what other studies found (Papenfuse et al., 2000; Cole 2001; Cole \& Hall, 2008). Only a little more than one third of the respondents in that area were overnight users. One reason for this may be the relative remoteness of some wilderness areas, especially in the Klamath National Forest. The Deschutes-Willamette and Stanislaus National Forests are in close proximity to urban settings, as well as major tourist destinations such as the Columbia River Gorge National Scenic Area. This allows recreationists to choose between camping and more developed lodging facilities such as hotels, lodges, or their own home.

Hiking and walking, camping and backpacking, and viewing natural features were the most popular primary activities. Those are typically common recreation activities for wilderness users (Stankey, 1980; Roggenbuck \& Watson, 1989).

All in all, despite changes in the sociodemographic make-up of the US population and with the exception of the high percentage of overnight use, the user and trip characteristics of the sample studied in this thesis are similar to what numerous previous research projects have found. 


\section{RQ2: What motivates visitors to recreate in the wilderness areas?}

Of the nine motivational items presented to the interviewees, the ones relating to the physical setting, such as to be outdoors (mean=4.74) and to experience natural surroundings (mean=4.73), achieved the highest ratings on average. These items were rated as a very important or extremely important motivation for wilderness recreation by more than $90 \%$ of the visitors.

Catharsis items such as for relaxation (mean=4.48) and to get away from the regular routine $($ mean $=4.57)$ were also very important motivations for recreating in a wilderness setting. Items describing challenge reasons for wilderness recreation, such as for physical exercise $($ mean $=4.27)$ and for the challenge or sport $($ mean=4.02), were rated as very important. The locus of control item to develop my skills (mean=3.55) and social items like for family recreation (mean $=3.70)$ and to be with my friends $($ mean=4.09), were considered the least important motivational factors for visiting the wilderness areas.

When asked for their primary reason to visit the wilderness, the enjoyment of the place itself (38.5\%) and the fact that the wilderness is a good place for the outdoor recreation activities they enjoy (38.4\%) were the answer choices most frequently chosen by respondents. Spending time with companions $(17.7 \%)$ and the proximity of the wilderness area to the visitor's home $(5.4 \%)$ were not as relevant.

These findings confirm results from earlier studies; Visitors recreate in wilderness to relax, enjoy nature and experience solitude. Social reasons are not as important for this kind of outdoor recreation setting (Graefe et al., 2000; Cole, 2001). Additionally, it may be important to note that a large portion of the sample was in their thirties or forties (see RQ1). A strong focus on achievement in one's professional career and a stressful family life are very typical for people in that age class (Lewis, 2009). This may also intensify those visitors' 
desire for relaxation, solitude, being outdoors, and connecting with nature in their leisure time, all of which were rated as major motivations for wilderness recreation.

\section{RQ3: What is the satisfaction level of respondents across the wilderness areas?}

Results from this study indicate high satisfaction levels across all wilderness areas. Overall, visitors were very satisfied with their recreation experience (mean=2.91). The fact that all quality attributes were rated as very good also indicates high visitor satisfaction with qualities such as wilderness experience (mean=4.42), environmental conditions $($ mean=4.40), quiet or solitude $($ mean=4.34), and lack of human influence (mean=3.94). The same was found when visitors were asked about their level of agreement with a battery of trip attributes. Wilderness recreationists thoroughly enjoyed their visit to the wilderness $($ mean=4.69), agreed that my trip to this wilderness was well worth the money I spent on it (mean=4.68), and that this wilderness and its surroundings are in a good condition $($ mean $=4.30)$.

High satisfaction levels are very common for wilderness recreation and thus the results from this study are in accordance with findings from earlier studies (Lucas, 1980; Dawson \& Watson, 2010).

\section{RQ4: What are the levels of crowding and conflict across the wilderness areas?}

Crowding and conflict are not an issue in the wilderness areas studied in this thesis. Less than five percent of visitors had conflicts with other parties. Crowding levels met the expectations of a little less than half of the sample (45.5\%). Accordingly, visitors did not feel crowded at all, which was indicated by an average score of 2.25 on a nine point scale.

Almost the entire sample preferred to recreate in small groups of five or less people $(81.9 \%)$ or medium groups of six to fifteen people (12.6\%). Hardly any of the respondents favored large groups of sixteen to twenty-five people $(<1 \%)$. This indicates that visitors agree with and support management regulations such as group size limits to 25 in the wilderness 
areas in Klamath National Forest, 15 in the Stanislaus National Forest, and 12 in the Oregon National Forests.

The average acceptable percentage of time in sight of other groups was higher $(22.0 \%)$ than the actual percentage of time spent in sight of other groups (16.5\%). Visitors encountered a little over five other groups during their visit (mean=5.13), which is slightly less than the indicated acceptable number of group encounters $($ mean= 5.61).

Consequently, the vast majority of respondents reported that they could find places to recreate without feeling crowded (mean=4.50) and without conflict from other visitors (mean=4.57). These findings are very consistent with earlier studies (Dawson\& Watson, 2000; Hall\& Cole, 2007). Previous research indicated that there tends to be a negative correlation between perceived crowding, encounters with other visitors, and satisfaction levels (Dawson \& Watson, 2010). The findings from this study support this: As discussed in research questions 2 and 3, satisfaction levels were very high and perceived crowding levels were low. The reason may be the fact that the respondents' crowding expectations were very realistic and thus actually encountering other visitors or being in sight of other groups while recreating was not evaluated as negative. According to Burns et al. (2003) repeat visitors are more likely to have accurate expectations than first time visitors. Since this variable did not occur on all survey instruments it was not included in this thesis, but may provide an explanation for the reported expected crowding levels.

Even though the majority of visitors disagreed that they avoided some places at this wilderness because there were too many people there (mean=2.09), that the number of people at this wilderness reduced their enjoyment (mean=1.90), and that the behavior of other visitors interfered with the quality of their recreation experience (mean=1.76), there was still a considerable amount of 7.2 to $17.5 \%$ of respondents who agreed with the above statements. This is especially concerning since "opportunities for solitude" (Wilderness Act, 1964, 
Section 2c) is one of the characteristics that legally define wilderness. These findings may represent the fact that across all wilderness areas there were several groups that exceeded the respective group size limit. Visitors, who expect solitude and then encounter large youth backpacking camps, are likely to evaluate the above statements more negatively. This issue and potential management implication are further discussed later in this thesis.

Authors such as Leung and Marion (2000) have stressed that wilderness managers need to strive to provide opportunities for high quality recreation experiences for all visitors. Therefore, even though overall perceived crowding levels were low and visitors expressed a rather indifferent evaluation of the effect other visitors had on their recreation experience, management action may become necessary if similar observations as the ones just discussed are made in future studies.

RQ5: Are there significant differences in visitors' motivations, satisfaction, and perceived crowding levels between the wilderness areas in the Deschutes-Willamette, Klamath, and

\section{Stanislaus National Forests?}

As expected, the investigation of motivation, satisfaction, and crowding variables revealed many statistically significant differences for the three regions. Even though general patterns - similar motivations, high satisfaction, and little to no crowding and conflict - were apparent for all three regions, there were still quite some statistically significant differences between the individual regions. This is similar to Lucas' (1980) findings. Based on data from a comparison of nine wilderness areas the author reported similar overall patterns in terms of satisfaction and crowding as this study, but also discussed findings that indicate slight differences between individual wilderness areas. This has important implications for wilderness managers, which will be discussed later. On the other hand, Palso and Graefe's (2007) study on perceptions of wilderness users in the eastern and western US revealed 
hardly any significant differences between the two regions. This is somewhat different to what this thesis found with regards to the comparison between regions.

Only one of the nine motivational items did not produce significant results. Visitors in the Deschutes- Willamette National Forests (mean=4.74), the Stanislaus National Forest (mean=4.74), and the Klamath National Forest (mean=4.75), all rated to be outdoors as an extremely important reason to recreate in wilderness. The second motivational item describing the natural setting to experience natural surroundings did reveal differences at the 5\% significance level. To experience natural surroundings was of greater importance to the recreationists in the Deschutes-Willamette National Forests (mean=4.73) and the Stanislaus National Forest (mean=4.76), compared to those recreating in the wilderness areas in northern California (mean=4.67), $(\mathrm{F}=4.260 ; \mathrm{p}<.05)$. Both motivational items relating to the physical setting received the highest importance ratings of all items on the list. These items also revealed no or relatively weak statistically significant differences between the three regions. This supports the conclusions other authors have made: The most important reason for people to recreate in wilderness settings is to be in and connect with nature (Graefe et al., 2000; Cole, 2001).

The second most important motivation for visitors in all three regions was the set of catharsis items. Even though there were significant differences between the three regions, the average importance rankings for each region reflect the overall order of importance of motivational items, which was discussed for research question 2 in this thesis and has been shown in previous studies (Graefe et al. 2000; Cole, 2001). Wilderness visitors are strongly motivated by items describing the natural setting and catharsis items. Social reasons and skill development play a minor role.

For relaxation was more important to visitors in the wilderness areas in the Stanislaus National Forest (mean=4.58) than to the ones in the wilderness areas of the Deschutes- 
Willamette National Forests $($ mean=4.43) and the Klamath National Forest $($ mean=4.41), $(\mathrm{F}=12.223 ; \mathrm{p}<.001)$. One potential explanation for this finding may be that many respondents in the Stanislaus National Forest were from highly urbanized parts of the state, such as the San Francisco Metro Area. It is likely that visitors from such significant business location are working in very demanding jobs and are constantly confronted with urban nuisances such as nerve racking commutes to work. In their leisure time they are very likely looking for compensation for such stressful lifestyles by seeking relaxation in wilderness.

To be with my friends was a less important reason to visit the wilderness for the recreationists in the Klamath (mean=3.90) and Deschutes-Willamette National Forests $($ mean $=4.00)$ than for the respondents in the Stanislaus National Forest (mean=4.28), $(\mathrm{F}=20.981 ; \mathrm{p}<.001)$. Again, this may be explained by the Stanislaus visitors' desire for relaxation and the need to get away from an urban lifestyle characterized by permanent social interactions. To develop my skills was more relevant for wilderness users in the Stanislaus $($ mean $=3.71)$ and the Deschutes-Willamette National Forests $($ mean=3.42) than for their counterparts in the Klamath National Forest (mean=3.50), $(\mathrm{F}=11.851 ; \mathrm{p}<.001)$.

Besides the outstanding importance of being in nature and relaxation as motivations for wilderness recreation, these results indicate that visitors in each region are still somewhat special in their motives. It appears that Stanislaus visitors are somewhat different in their motivation than users in the other national forests. The above example shows that recreationists in the Stanislaus National Forest were not just more motivated by skill development and relaxation reasons, but also placed higher importance on being with friends than visitors in the other National Forests. A large number of visitors in this area came from the densely populated urban areas such as Sacramento or the San Francisco Metro Area. Focus on their own interests and skills while being in a relaxing natural environment may be 
more important for visitors that are potentially living a hectic urban life. This is useful information for making well-informed management decisions in these wilderness areas.

Similar results were produced for the comparison of visitor satisfaction in the three regions. Generally, it appears that wilderness recreationists in the Stanislaus National Forest are somewhat more satisfied with their overall experience as well as with specific trip attributes. Overall satisfaction levels were higher in the Stanislaus (mean=2.93) and Klamath National Forests (mean= 2.96) than in the Deschutes-Willamette National Forest (mean= 2.89), $(\mathrm{F}=9.915 ; \mathrm{p}<.001)$. The same was true for satisfaction with the quality of wilderness characteristics such as quiet and solitude and wilderness experience. The quality of both items was rated higher by visitors in the Stanislaus and Klamath National Forests than the recreationists the Deschutes-Willamette National Forests. Lack of human influence was evaluated as better by wilderness recreationists in the Stanislaus National Forest compared to the other two National Forests, whereas environmental conditions only produced significant results for the comparison between the Deschutes-Willamette (mean=4.36) and the Stanislaus National Forests (mean=4.45), $(\mathrm{F}=3.151 ; \mathrm{p}<.05)$.

All trip attributes produced significant results and again visitors in the wilderness areas in the Stanislaus National Forest generally expressed higher satisfaction than recreationists in the other forests. They more strongly agreed that their trip was well worth the money they spent on it and that the wilderness and its surroundings are in a good condition. Visitors in both Californian National Forests more strongly agreed that they thoroughly enjoyed their visit to the wilderness than the Oregon portion of the sample. As mentioned before, one reason for this could be the visitors' origin. Visitors from more populated areas may be more likely to enjoy every aspect of their wilderness visit, which is a contrast to the stressful urban lifestyle. This approach has been discussed in other studies that compare recreation experiences in different wilderness areas (Palso \& Graefe, 2007). 
Findings from Cole's (2001) comparison of day and overnight users' satisfaction in several wilderness areas offer a potential explanation for the high satisfaction ratings in the large and comparatively remote wilderness areas in the Klamath National Forest. Cole's (2001) study revealed that even though overall satisfaction was high amongst all users, a lower percentage of visitors in the highly used areas such as the Three Sisters Wilderness reported high satisfaction levels (Cole, 2001). Findings from this thesis and Cole's (2001) study indicate that visitors are more satisfied in wilderness areas that are not as highly used or that are large enough to disperse use effectively. This shows that opportunities for solitude, one of the wilderness characteristics as defined by the Wilderness Act of 1964, should always be a management priority in order to provide visitors with opportunities for high quality recreation experiences.

The results for the comparison of crowding perceptions in the three regions support the overall finding from research question 4 in this thesis: Even though crowding levels are low across all regions, wilderness recreationists in the Stanislaus (mean=2.23) and Deschutes-Willamette National Forests (mean=2.34) still expressed slightly higher feelings of crowding than respondents in the Klamath National Forest (mean=2.04), $(F=5.700 ; p<.01)$. This may have to do with the fact that the wilderness areas in the Klamath National Forest are simply not as heavily visited. The reason for the overall very low feelings of crowding, even in high use wilderness areas on the Deschutes and Willamette National Forests, may be that visitors expect high use in those areas. According to Stankey (1980) visitors who expect high use are more crowding tolerant than those who expect low use.

However, since generally visitors did not feel crowded at all in all wilderness areas, those differences between the regions may be rather irrelevant from a management point of view. 


\section{RQ6: Are there significant differences in trip characteristics, motivations, satisfaction, crowding and conflict between female and male visitors?}

Overall, female respondents were more likely to be on a day trip, whereas male respondents were more likely to be on an overnight trip. Regardless if they were on a day or overnight trip, men spent significantly more time in wilderness than women. This is very consistent with what past research has shown. Cole and Hall (2005) found that $42 \%$ of wilderness day users were female. Cole (2001) stated that even though there are more male visitors for both day and overnight users, the proportion of females is larger for day use than for overnight use.

The analysis of motivations for wilderness recreation revealed many significant differences between the two user groups. Even though all nine motivational items were rated as very important or extremely important by both groups, females placed higher importance on every single item. In seven cases, those differences were significant. The only items that were not rated significantly different by male and female respondents were for the challenge or sport and to develop my skills. Higher importance ratings by females have been observed in other studies (Tarrant et al., 1999). A sound explanation as to why that is, is yet to be found.

Similar patterns were discovered for satisfaction ratings with quality attributes: Again, females reported higher ratings for all four attributes. However, only lack of human influence produced statistically significant differences between the two groups. Also, overall trip satisfaction was rated equally high by both groups (mean=2.91). As discussed previously, high overall satisfaction is typical for all user groups. Thus findings from this thesis are in accordance with results from other wilderness recreation studies (Lucas, 1980; Dawson \& Watson, 2010). 
The analysis of differences in crowding perceptions indicates that crowding and conflict are not an issue for either gender based user group. Equally small portions of both user groups experienced social conflict. Expected crowding levels did differ between males and females, but perceived crowding levels were not found to be significantly different. Actual and preferred crowding levels did not differ between male and female respondents. However, the level of agreement with six crowding and conflict attributes produced some significant results. As with motivations and satisfaction measures, females expressed stronger agreement and disagreement with all attributes, even though those differences were statistically significant in only four cases. Due to the general strong agreement that both men (mean=4.47) and women (mean=4.54) indicated for statement such as I had the opportunity without feeling crowded, these differences may not have many implications for wilderness managers. A possible reasoning for the male respondents' slightly greater sensitivity to crowding may be the fact that more males are overnight users. Past studies have shown that due to being motivated by factors like escape, relaxation, and experiencing solitude, overnight users are more likely to feel crowded than day users that are more likely to be motivated by social reasons. (Papenfuse et al., 2000).

Regardless of gender all visitors preferred to recreate in small groups of five or less people. Medium sized groups of six to fifteen people were preferred by a larger proportion of men $(13.1 \%)$ than women $(11.5 \%)$. Given the fact that females generally place more importance on social reason to recreate in wilderness and often perceive safety constraints, especially when recreating alone, larger group sizes would have been expected for this user group (Little, 2002; Lee et al., 2007). 


\section{RQ6a: Can a typology be derived from variables such as motivations, satisfaction levels, perceived crowding and trip characteristics for female and male visitors?}

So far it has been shown that overall there are indeed statistically significant differences between male and female wilderness recreationists. This implies that certain individual characteristics are typical for each of the two user groups. However, as discussed for research question 5, regardless of gender there are also differences in measures of social carrying capacity and visitor's motivations between the three regions studied in this thesis. This research question aimed at deriving typologies for male and female visitors. Thus, it was tested if the overall findings of gender based differences across all wilderness areas (research question 6) hold true for each of the three regions.

First, valid percentages for female and male users in each of the three regions were analyzed. The proportion of females recreating in wilderness was higher in the Deschutes and Willamette National Forests than in the Klamath National Forest. The wilderness areas in the Stanislaus National Forest received less female visitors than the other regions. This is only partially consistent with the most recent round of data collected through the Forest Service's National Visitor Use Monitoring program (NVUM) in the three regions. The analysis of NVUM data revealed $42 \%$ female visitors in the Deschutes and Willamette National Forests' wilderness areas, $40.2 \%$ in the Stanislaus National Forest and only $24.4 \%$ in the Klamath National Forest (USDA Forest Service, n.d.). In addition to the regional differences already discussed in research question 5, these variations in the gender specific make-up of wilderness visitors are another example for differences between regions.

Second, the variables that produced significant results in research question 6 were tested again for each individual region. The importance rating for motivational items for the wilderness areas in the Deschutes-Willamette National Forests supported earlier findings: All 
items were rated as more important by female respondents than by male respondents. With the exception of to develop my skills all of those differences were significant.

Female visitors in the wilderness areas in the Stanislaus National Forest also rated all motivational items higher or at least the same as male respondents. However, only for physical exercise was rated as significantly more important by the female portion of the sample. The two most important motivational items to experience natural surroundings and to be outdoors achieved identical average importance ratings by both groups.

The comparison of motivations between male and female visitors for the Klamath National Forest did not produce any significant results. Interestingly though to get away from the regular routine, for the challenge or sport, and for physical exercise was evaluated as slightly more important by male respondents than by their female counterparts. One explanation for this could be the high proportion of male visitors and overnight use in this region. Backcountry backpacking trips give people a break from their everyday lives and are in contrast to their regular routine. Also, those trips often are mentally and physically more challenging than day trips.

Considering statistical significant results, Tarrant et al.'s (1999) finding that females place higher importance on motivational items only seems to hold true for a certain region (Deschutes- Willamette National Forests).

Male visitors in the wilderness areas in the Deschutes and Willamette National Forests recreated longer than females, regardless if they were on a day or overnight trip. There were no differences between the two groups with regards to trip length in the Californian wilderness areas, except for male day users in the Klamath National Forest who spent more hours recreating than female day users.

The three satisfaction attributes lack of human influence, this wilderness and its surroundings are in good condition, and I thoroughly enjoyed my visit to this wilderness, 
which produced significant results in research question 6 , were also significant in the wilderness areas in the Deschutes and Willamette National Forests; Women were more satisfied and indicated higher levels of agreement than men. For the Stanislaus National Forest women more strongly agree with I thoroughly enjoyed my visit to this wilderness. No differences for satisfaction measures were found for male and female visitors in the Klamath National Forest.

Of the four overall significant crowding and conflict items two were significant for the Oregon wilderness areas. Women in these wilderness areas, as well as in the Klamath National Forest, more strongly agreed that they had the opportunity to recreate without feeling crowded. The other people at this wilderness increased my enjoyment triggered a higher level of agreement for females in the Deschutes and Willamette National Forests only. Female recreationists in the Klamath reported stronger agreement with the statement I could find places to recreate without conflict from other visitors than males. Women in the Stanislaus National Forest indicated stronger disagreement with the statement that they avoided some places at this wilderness because there were too many people there.

All in all, the gender-based comparison for each region revealed that it is not possible to derive universal typologies for male and female wilderness users. Even though the analysis of gender-based differences across all wilderness areas (research question 6) produced results, which are in accordance to what authors such as Cole (2001) or Tarrant et al. (1999) suggested, there are also regional differences which do not allow for overall gender-based typologies. There are indeed similar overall trends: Females are more likely to be day users, they don't spent as much time in wilderness as men, they report higher motivation and satisfaction scores, and they are more likely to be motivated by social reasons. Still, none of these variables were statistically significant for the comparison between males and females in each of the three individual regions. 
Based on the findings from research question $6 \mathrm{a}$ it seems that female users in the wilderness areas in the Deschutes and Willamette National Forests are different from the female users recreating in the Californian wilderness areas. The data collected for this thesis do not give any indication why that is. A comparison of variables measuring sociodemographic and activity participation did not provide an obvious explanation for this finding. Neither did a comparison of US census data for each region.

Toth and Brown (1997) discussed the influence of social interactions on human behavior in general and women's self-perception in particular: „What if a particular geographic region and accompanying subculture do not necessarily expose women to [certain] factors? The experience of one's [...] gender through social interactions also contributes to personal evaluations of reality “( (p. 142).

The wilderness areas in the Deschutes and Willamette National Forests are in close proximity to the town of Bend, Oregon. Bend has been known as an outdoor recreation mecca and appears on rankings such as the "Best Adventure Towns in the US" on a regular basis. Therefore, especially outdoorsy people move there. In fact, Bend's population has more than quadrupled from a little over 20,000 in 1990 to almost 90,000 in 2015. One reason for the Oregon wilderness areas' high percentage of female visitors, that are different from the male proportion of the sample, could be that outdoorsy urban areas like Bend not just attract adventure-fond women, but also foster a safe and inspiring environment, one that shapes a certain kind of female wilderness recreationist. This potential explanation is supported by NVUM data. As the population of Bend has grown over the years, the proportion of females in wilderness has slightly increased from in $39.8 \%$ in 2008 to $42.0 \%$ in 2013 (USDA Forest Service, n.d.). Mowl and Towner (1995) explained this reciprocal relationship between places and their recreational users by saying "Leisure places are not 
simply physical areas on a map, they are individual human creations, which are in themselves the products of social, cultural, economic and political processes " ( p. 114).

\section{Management Implications}

The findings from this study have several implications for wilderness management. First, the data used in this thesis also revealed that not all visitors adhere to wilderness rules. There were thirteen cases in the Deschutes and Willamette National Forests where groups of more than 12 people recreated in wilderness. The group size limits for the three wilderness areas in that region is 12 . Several parties exceeded the permitted group size of 15 in the Stanislaus and 25 in the Klamath National Forests. One youth camp reportedly consisted of 90 children and ten adults. This should be carefully monitored and management action needs to be taken, if large groups recreating resulted in the deterioration of other visitors' wilderness recreation experience or if environmental concerns arose.

Second, even though some visitor characteristics (the majority is male, highly educated, there is a wide age range) and social carrying capacity attributes such as high levels of satisfaction, low crowding levels, and essentially non-existing conflict appear to be typical for wilderness recreation in general, each wilderness area and its visitors are somewhat unique. For instance, data from this study suggest wilderness areas in closer proximity to urban agglomerations may attract visitors that have different motivations than areas that are near to less urbanized areas. Amongst other factors, the individual wilderness area's visitors' motivations and expectations should be considered when management decisions are made. Taking users' motivations, expectations, and preferences into account can be especially important for potentially controversial decisions such as permit systems or group size limits. For instance, if visitors are motivated by relaxation and solitude reasons and expect to see only few small groups while recreating in wilderness, they may be more likely to accept rules and regulations that foster such conditions. 
Last, it is evident that females have become a very important user group in wilderness recreation. Therefore, it seems appropriate for managers to emphasize marketing towards females. Marketing towards females must not just focus on wilderness recreation, but could be expanded to related industries such as outdoor recreation gear sellers. Not just would female visitors be more likely to identify with more targeted marketing campaigns, but consequently the providing industries and agencies would benefit from tapping into a huge market. So far this has not been a priority. Considering findings from previous studies offers such as guided backpacking trips may be an option for women to recreate in wilderness without perceiving constraints regarding their personal safety. This could be one potential way for federal agencies to provide opportunities for high quality recreation experiences for everyone, including the type of female users who may otherwise be excluded from wilderness recreation due to safety constraints. In fact, increased long-term cooperation with outdoor recreation companies (e.g., Recreational Equipment, Inc. or REI) may be a great opportunity for federal agencies. Only recently REI started offering women-only backpacking trips that are led by experienced female guides. Destinations include iconic settings such as the backcountry of Yosemite National Park, the Appalachian Trail, and the Pacific Crest Trail, which runs through wilderness areas studied in this thesis. Offering such trips in wilderness areas where women are extremely underrepresented could help attracting more female users to these areas.

Generally, in order for federal agencies to set an example, it may be beneficial to include more females in management positions in the field of parks and recreation, particularly as wilderness managers.

\section{Recommendations for Future Research}

There are several recommendations for future research relating to the role of gender in wilderness recreation. 
Foremost, as with other minority groups, there is an urgent need for more research on the role of gender in outdoor recreation in general and wilderness recreation in particular. So far, studies investigating the role of gender in outdoor recreation usually applied a qualitative approach and were either of a very descriptive nature, or focused on gender-based leisure constraints. It would be beneficial to utilize mixed method studies or even focus on a quantitative approach in order to derive results that can be statistically analyzed, objectively interpreted, and compared against one another. Quantitative studies may also generate more useful and usable information for wilderness managers.

Furthermore, interdisciplinary research project could be helpful in order to find databased explanations for why females tend to report significantly higher ratings when asked for their motivations and, to some extent, when rating the importance of or satisfaction with trip attributes and qualities. As already stated this has not just been shown in this thesis, but in previous research as well. Studies involving outdoor recreation researchers, psychologists, and other social science researchers may produce more in-depth analysis of wilderness users, which would provide managers with a more thorough understanding of their visitors' behavior.

Future studies in wilderness areas near popular outdoor recreation towns like Bend, OR, Missoula, MT, Sedona, AZ, or Boulder, CO would help to better understand the influence a region's cultural and societal characteristics have on wilderness recreation behavior. This could not just potentially enable a more sound reasoning for the findings presented in this thesis, but would also provide wilderness managers in those areas with valuable information about their visitors.

Last, it may eventually become necessary to rethink gender theory. Traditionally, research not just in outdoor recreation, but in most scientific disciplines, focuses on gender as a dichotomous variable. However, in today's society it is not uncommon for people to 
identify as neither male nor female. Thus, including the open-ended option Other into survey instruments in outdoor recreation research would only be logical.

\section{Conclusions}

The overall purpose of this study was to identify gender-based differences in wilderness recreation, as well as regional differences. This thesis has shown that even though there are characteristics that appear to hold true across all wilderness areas, each region's visitors are somewhat unique in their demographic make-up, their motivations, perception, and experiences. Thus, research investigating wilderness recreation in individual regions remains critical. Furthermore, it is obvious that there is not just plenty of opportunity for research on the role of gender in wilderness recreation, but an immense need for such studies. Wilderness managers need to understand the increasingly important minority group of female users in order to provide equal opportunities for high quality recreation experiences for all user groups.

It was found that even though there are certain trends for gender-based difference in wilderness recreation, these have to be evaluated for each individual region. Due to regional differences it is difficult to derive generally valid typologies of male and female wilderness recreationists.

Nevertheless, findings from this thesis imply some important conclusions for wilderness management. Even more than fifty years after its creation the Wilderness Act still accurately describes and defines what characterizes wilderness, and what kind of recreation these special areas offer to all visitors. Recreationists come to wilderness because they want to experience nature in one of its purest forms, because they seek opportunities for solitude or primitive recreation. It is crucial that despite challenges such as increasing visitation, budget constraints, and political pressure future management decisions continue to ensure the protection of the resource and fulfillment of visitors' expectations by adhering to that 
exemplary piece of legislation. In order to efficiently and effectively do that, research on wilderness recreation in general, and on both specific areas and user groups in particular was, is, and always will be an important foundation for well-informed management decisions that ensure the protection and enjoyment of the National Wilderness Preservation System for all people. 


\section{REFERENCES}

Bacon, J., Manning, R., Johnson, D., \& Kamp, M. V. (2001). Norm stability: a longitudinal analysis of crowding and related norms in the wilderness of Denali National Park and Preserve. George Wright Forum, Vol. 18, 62-71.

Bialeschki, M. D., \& Henderson, K. A. (1993). Expanding outdoor opportunities for women. Parks \& Recreation (Arlington), 28(8), 36-40.

Borrie, W. T., Pohl, S. L., \& Patterson, M. E. (2000). Women, wilderness, and everyday life: A documentation of the connection between wilderness recreation and women's everyday lives. Journal of Leisure Research, 32, 415- 434.

Burns, R.C. (2000) Methodological issues associated with customer satisfaction measurement and market segmentation at water-based recreation areas. Unpublished Doctoral Dissertation, The Pennsylvania State University.

Burns, R. C., Graefe, A. R., \& Absher, J. D. (2003). Alternate measurement approaches to recreational customer satisfaction: Satisfaction-only versus gap scores. Leisure Sciences, 25(4), 363-380.

Burns, R. C., \& Graefe, A. R. (2005). Customer satisfaction at water-based outdoor recreation settings: understanding differences across market segments. LARNet-The Cyber Journal of Applied Leisure and Recreation Research, (December).

Ching-hua, H., Sasidharan, V., Elmendorf, W., \& Willits, F. K. (2005). Gender and ethnic variations in urban park preferences, visitation, and perceived benefits. Journal of leisure research, 37(3), 281-306.

Coble, T. G., Selin, S. W., \& Erickson, B. B. (2003). Hiking alone: Understanding fear, negotiation strategies and leisure experience. Journal of Leisure Research, 35(1), 1.

Cole, David N. (2001). Day users in wilderness: how different are they? Ogden, UT: U.S. Department of Agriculture, Forest Service, Rocky Mountain Research Station Res. Pap. RMRS-RP-31.

Cole, D. N., Petersen, M., \& Lucas, R. C. (1987). Managing wilderness recreation use: common problems and potential solutions. US Forest Service, Intermountain Forest and Range Experiment Station, Research Paper INT-230.

Cole, D. N., Turner, D. L., \& Reynolds, P. S. (2000). Wilderness recreation use estimation: a handbook of methods and systems. US Forest Service, Rocky Mountain Research Station, General Technical Report RMRS-GTR-56.

Cole, D. N., \& Hall, T. E. (2005). Wilderness visitors and experiences in Oregon and Washington: Trailhead surveys in thirteen Forest Service wildernesses. Retrieved from http://www.webpages.uidaho.edu/wrc/Publications/Cole_Hall_2005_13_Trailheads_Su rvey.pdf 
Cole, D. N., \& Hall, T. E. (2008). Wilderness visitors, experiences, and management preferences: How they vary with use level and length of stay.US Forest Service, Rocky Mountain Research Station, Research Paper RMRS-RP-71.

Cordell, H. K., McDonald, B. L., Teasley, R. J., Bergstrom, J. C., Martin, J., Bason, J., \& Leeworthy, V. R. (1999). Outdoor recreation participation trends. Outdoor recreation in American life: A national assessment of demand and supply trends, 219-321.

CCRVC. (2014). Gender distribution of campers in Canada in 2014. Retrieved from http://www.statista.com/statistics/449514/gender-distribution-of-campers-canada/.

Dawson, C. P., \& Watson, A. E. (2000). Measures of wilderness trip satisfaction and user perceptions of crowding. USDA Forest Service Proceedings RMRS-P-15, 4, 93-98.

Donnelly, M. P., Vaske, J. J., DeRuiter, D. S., \& King, T. B. (1996). Person-occasion segmentation of state park visitors. Journal of Park and Recreation Administration, 14(2), 95-106.

Dougherty, M. A., Pierskalla, C. D., Selin, S., Smith, D., Bricker, K., \& Kauffman, R. (2005). The changes in life effectiveness following ropes course participation for becoming an outdoors-woman (BOW) participants. Morgantown: West Virginia University Libraries.

Driver, B.L. (1983). Master list of items for Recreation Experience Preference scales and domains. Unpublished document. USDA Forest Service, Fort Collins, CO: Rocky Mountain Forest and Ranger Experiment Station.

Driver, B.L. and Tocher, S. R. (1970). Toward a behavioral interpretation of recreational engagements, with implications for planning. Elements of outdoor recreation planning. Ann Arbor, MI: University of Michigan Press, 9-31.

Frissel, S., \& Stankey, G. (1972). Wilderness environmental quality: Search for social and ecological harmony. Proceedings of the Society of American Foresters Annual Conference, Hot Springs, AR: Society of American Foresters, 170-183.

Graefe, A. R., Thapa, B., Confer, J. J., \& Absher, J. D. (2000). Relationships between trip motivations and selected variables among Allegheny National Forest visitors. USDA Forest Service Proceedings RMRS-P-15, 4, 107-113.

Hall, Troy E.; Cole, David N. (2007). Changes in the motivations, perceptions, and behaviors of recreation users: Displacement and coping in wilderness. Res. Pap. RMRS-RP-63. Fort Collins, CO: U.S. Department of Agriculture, Forest Service, Rocky Mountain Research Station. 37 p.

Hartmann, L. A., \& Cordell, H. K. (1989). An overview of the relationship between social and demographic factors and outdoor recreation participation. Outdoor Recreation Benchmark 1988: Proceedings of the National Outdoor Recreation Forum, 255-274. 
Heberlein, T. A., \& Vaske, J. J. (1977). Crowding and visitor conflict on the Bois Brule River. University of Wisconsin. Water Resources Center Technical Report OWRT A066-WAS, Madison.

Hendee, J. C., Stankey, G. H., \& Lucas, R. C. (1978). Wilderness management (No. 1365). Washington D.C.: Forest Service, US Department of Agriculture.

Henderson, K. A. (1996). One size doesn't fit all: The meanings of women's leisure. Journal of Leisure Research, 28(3), 139-154.

Jacob C.R. \& Schreyer R. (1980). Conflict in outdoor recreation: A theoretical perspective. Journal of Leisure Research, 24, 348- 360.

Johnson, C. Y., Bowker, J. M., \& Cordell, H. K. (2001). Outdoor recreation constraints: An examination of race, gender, and rural dwelling. Southern Rural Sociology, 17(1), 111133.

Lee, S. H., Graefe, A. R., \& Li, C. L. (2007). The effects of specialization and gender on motivations and preferences for site attributes in paddling. Leisure Sciences, 29(4), 355-373.

Leung, Y. F., \& Marion, J. L. (2000). Recreation impacts and management in wilderness: A state-of-knowledge review. Cole, DN, McCool, SF, Borrie, WT, O'Loughlin, J.,(comps), Proceedings: Wilderness Science in a Time of Change, 5.

Lewis, J. (2009). Work-family balance, gender and policy. Northhampton, MA: Edward Elgar Publishing.

Li, C. L., Zinn, H. C., Barro, S. C., \& Manfredo, M. J. (2003). A cross-regional comparison of recreation patterns of older hunters. Leisure Sciences, 25(1), 1-16.

Lime, D., \& Stankey, G. (1971). Carrying capacity: Maintaining outdoor recreation quality. Recreation Symposium Proceedings. USDA Forest Service, 174-184.

Little, D. E. (2002). Women and adventure recreation: Reconstructing leisure constraints and adventure experiences to negotiate continuing participation. Journal of Leisure Research, 34(2), 157-177.

Lucas, R. C. (1980). Use Patterns and Visitor Characteristics, Attitudes and Preferences in Nine Wilderness and Other Roadless Areas. US Forest Service, Intermountain Forest and Range Experiment Station, Research Paper INT-253.

Lucas, R. C. (1973). Wilderness: a management framework. Journal of Soil and Water Conservation, 28(4), 150-154.

Lucas, R. C., \& Oltman, J. L. (1971). Survey sampling wilderness visitors. Journal of Leisure Research, 3(1), 28-43.

Marion, J. L. (1998). Recreation ecology research findings: Implications for wilderness and park managers. Proceedings of the national outdoor ethics conference, 188-196. 
Manfredo, M. J., Driver, B. L., \& Tarrant, M. A. (1996). Measuring leisure motivation: A meta-analysis of the recreation experience preference scales. Journal of leisure Research, 28(3), 188-213.

McNiel, J. N., Harris, D. A., \& Fondren, K. M. (2012). Women and the wild: Gender socialization in wilderness recreation advertising. Gender Issues, 29, 39-55.

Merigliano, L., \& Smith, B. (2000). Keeping wilderness wild: increasing effectiveness with limited resources. Wilderness Science in a Time of Change Conference, Proceedings RMRS-P-15-VOL-4. Ogden, UT: U.S. Department of Agriculture, Forest Service, Rocky Mountain Research Station, 236-242.

Mitten, D. (1992). Empowering girls and women in the outdoors. Journal of Physical Education, Recreation and Dance, 63 (2), 56-60.Education, Recreation and Dance, 63 (2), 56-60.

Mowl, G., \& Towner, J. (1995). Women, gender, leisure and place: towards a more 'humanistic'geography of women's leisure. Leisure Studies, 14(2), 102-116.

Oye, G. (2001). A new wilderness recreation strategy for national forest wilderness. International Journal of Wilderness, 7(1), 13-15.

Palso, N. and Graefe A. (2008). Transcontinental Wilderness survey: Comparing perceptions between Wilderness users in the eastern and western United States. Proceedings of the 2007 Northeastern Recreation Research Symposium, 232- 238.

Papenfuse, M. K., Roggenbuck, J. W., \& Hall, T. E. (2000). The rise of the day visitor in wilderness: should managers be concerned. Wilderness Science in a Time of Change Conference, Proceedings RMRS-P-15-VOL-4. Ogden, UT: U.S. Department of Agriculture, Forest Service, Rocky Mountain Research Station, 148-154.

Parasuraman, A., Zeithaml, V.A., \& Berry, L.L. (1988). SERVQUAL: a multi-item scale for measuring consumer perceptions of service quality. Journal of Retailing, 64(1), 12-40.

Roggenbuck, J. W., \& Watson, A. E. (1989). Wilderness recreation use: the current situation. Outdoor Recreation Benchmark 1988: Proceedings of the National Outdoor Recreation Forum. Gen. Tech. Rep. SE-52, 346-356.

Roggenbuck, J. W., Williams, D. R., \& Watson, A. E. (1993). Defining acceptable conditions in wilderness. Environmental Management, 17(2), 187-197.

Sali, M., \& Kuehn, D. (2006). Gender- based motivation of non- residential birdwatchers in New York State: a qualitative study. Proceedings of the 2006 Northeastern Recreation Research Symposium. USDA Forest Service General Technical Report GTR-NRS-P$14,318-325$.

Schuster, R. M., Tarrant, M. A., \& Watson, A. E. (2003). The social values of wilderness. Proceedings of the 2003 Northeastern Recreation Research Symposium. USDA Forest Service General Technical Report GTR-NE-317, 356- 365. 
Shelby, B., \& Heberlein, T.A. (1986). Carrying Capacity in Recreation Settings. Corvallis, OR: Oregon State University Press.

Shelby, B., Vaske, J. J., \& Heberlein, T. A. (1989). Comparative analysis of crowding in multiple locations: Results from fifteen years of research. Leisure Sciences, 11(4), 269291.

Stankey, G. H. (1980). A comparison of carrying capacity perceptions among visitors to two wildernesses. Ogden : Intermountain Forest and Range Experiment Station, Forest Service, U.S. Dept. of Agriculture.

Stankey, G. H., McCool, S. F., \& Stokes, G. L. (1984). Limits of acceptable change: a new framework for managing the Bob Marshall Wilderness complex. Western Wildlands, 10(3), 33-37.

Stankey, G. H. (2000). Future trends in society and technology: Implications for wilderness research and management. Wilderness Science in a Time of Change Conference, Proceedings RMRS-P-15-VOL-4. Ogden, UT: U.S. Department of Agriculture, Forest Service, Rocky Mountain Research Station, 10-23.

Sureshchandar, G. S., Rajendran, C., \& Anantharaman, R. N. (2002). The relationship between service quality and customer satisfaction-a factor specific approach. Journal of services marketing, 16(4), 363-379.

Tarrant, M. A., Smith, E., \& Cordell, H. K. (1999). Recreation visitor preferences for and perceptions of outdoor recreation setting attributes. In H. Cordell, C. Betz, \& J. Bowker (Eds.): Outdoor recreation in American life: a national assessment of demand and supply trends. (pp. 412-431). Champaign, IL: Sagamore Publishing.

USDA Forest Service (n.d.): Natural Resource Manager: Welcome to USDA Forest Service National Visitor Use Monitoring. Retrieved from http://apps.fs.fed.us/nfs/nrm/nvum/results/

Vaske, J. J., Donnelly, M. P., Heberlein, T. A., \& Shelby, B. (1982). Differences in reported satisfaction ratings by consumptive and nonconsumptive recreationists. Journal of Leisure Research, 14(3), 195.

Vaske, J. J., \& Shelby, L. B. (2008). Crowding as a descriptive indicator and an evaluative standard: Results from 30 years of research. Leisure Sciences, 30(2), 111-126.

Vaske, J., \& Roemer, J. (2013): Differences in overall satisfaction by consumptive and nonconsumptive recreationists: A comparative analysis of three decades of research. Human Dimensions of Wildlife, 18, 159-180.

Wagar, J.A. (1964). The Carrying capacity of wild lands for recreation. Forest Science Monograph 7. Washington, DC: Society of American Foresters.

Wagar, J.A. (1974). Recreational carrying capacity reconsidered. Journal of Forestry, 72, 274-278. 
Washburne, R. F. (1982). Wilderness recreational carrying capacity: are numbers necessary?. Journal of Forestry, 80(11), 726-728.

Watson, A. E., Niccolucci, M. J., \& Williams, D. R. (1994). The nature of conflict between hikers and recreational stock users in the John Muir Wilderness. Journal of Leisure Research, 26, 372-385.

Wilderness Act. (1964). 16 USC 1131-1136. Retrieved from http://wilderness.net/index.cfm?fuse=NWPS\&sec=legisact.

Yerkes, R., \& Miranda, W. (1982). The need for research in outdoor education programs for women. Journal of Physical Education, Recreation, and Dance, 37(4), $82-85$. 


\section{APPENDIX A: SURVEY INSTRUMENT}

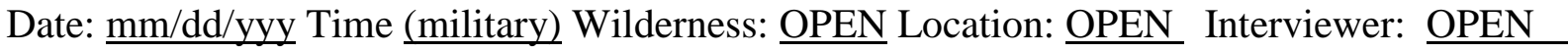

\section{Modified 2010 Deschutes and Willamette NF \& Klamath and Stanislaus NF}

\section{Wilderness Surveys}

Please take a few minutes to answer these questions. We are trying to learn more about the recreation use of this wilderness and your impressions are important to us. All answers will

be kept confidential.

1. Overall, how would you rate your trip in this wilderness?

$\underline{1.1 \%}$ Not satisfied

$\underline{6.5 \%}$ Fairly satisfied

92.4\% Very satisfied Mean $=2.91 \quad$ Comments: $\underline{\text { See Appendix }}$

2. Please look at this list of statements that address your feelings about this trip to this wilderness.

Please indicate your level of agreement with each of the statements listed below.

\begin{tabular}{|c|c|c|c|c|c|c|c|}
\hline & 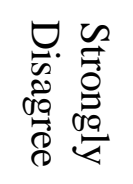 & 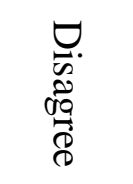 & 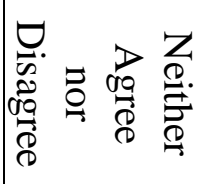 & $\underset{\substack{\infty \\
\mathbb{d}}}{D}$ & 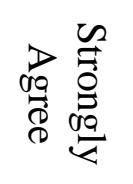 & $\frac{Z}{>}$ & \begin{tabular}{l}
3 \\
$\stackrel{3}{\Xi}$ \\
\multirow{3}{*}{}
\end{tabular} \\
\hline $\begin{array}{l}\text { I thoroughly enjoyed my visit to this } \\
\text { wilderness }\end{array}$ & $<1 \%$ & $<1 \%$ & $1.5 \%$ & $26.4 \%$ & $71.6 \%$ & --- & 4.69 \\
\hline $\begin{array}{l}\text { I had the opportunity to recreate } \\
\text { without feeling crowded }\end{array}$ & $<1 \%$ & $1.9 \%$ & $5.2 \%$ & $32.5 \%$ & $59.7 \%$ & $<1 \%$ & 4.50 \\
\hline $\begin{array}{l}\text { I could find places to recreate without } \\
\text { conflict from other visitors }\end{array}$ & $<1 \%$ & $<1 \%$ & $4.4 \%$ & $29.3 \%$ & $64.5 \%$ & $<1 \%$ & 4.57 \\
\hline $\begin{array}{l}\text { My trip to this wilderness was well } \\
\text { worth the money I spent to take it }\end{array}$ & $<1 \%$ & $<1 \%$ & $3.9 \%$ & $21.5 \%$ & $72.7 \%$ & $1.1 \%$ & 4.68 \\
\hline $\begin{array}{l}\text { I was disappointed with some aspects } \\
\text { of my visit to this wilderness }\end{array}$ & $48.8 \%$ & $27.8 \%$ & $10.9 \%$ & $8.7 \%$ & $2.5 \%$ & $1.4 \%$ & 1.87 \\
\hline $\begin{array}{l}\text { I avoided some places at this } \\
\text { wilderness because there were too } \\
\text { many people there }\end{array}$ & $43.6 \%$ & $24.4 \%$ & $13.3 \%$ & $13.5 \%$ & $4.0 \%$ & $1.3 \%$ & 2.09 \\
\hline $\begin{array}{l}\text { The number of people at this } \\
\text { wilderness reduced my enjoyment }\end{array}$ & $44.9 \%$ & $28.9 \%$ & $16.7 \%$ & $6.4 \%$ & $1.9 \%$ & $1.2 \%$ & 1.90 \\
\hline $\begin{array}{l}\text { The behavior of other people at this } \\
\text { wilderness interfered with the } \\
\text { quality of my experience [if agree, } \\
\text { specify behavior] }\end{array}$ & $51.9 \%$ & $26.5 \%$ & $12.2 \%$ & $5.2 \%$ & $2.0 \%$ & $2.2 \%$ & 1.76 \\
\hline $\begin{array}{l}\text { The other people at this wilderness } \\
\text { increased my enjoyment }\end{array}$ & $12.0 \%$ & $16.1 \%$ & $42.1 \%$ & $17.1 \%$ & $9.0 \%$ & $3.8 \%$ & 2.95 \\
\hline $\begin{array}{l}\text { This wilderness and its surroundings } \\
\text { are in good condition }\end{array}$ & $<1 \%$ & $2.7 \%$ & $7.5 \%$ & $43.6 \%$ & $44.7 \%$ & $<1 \%$ & 4.30 \\
\hline
\end{tabular}


3. Overall, how would you rate the quality of each of the following at this wilderness?

\begin{tabular}{|l|c|c|c|c|c|c|c|}
\hline & Awful & Fair & Good & $\begin{array}{c}\text { Very } \\
\text { Good }\end{array}$ & Excellent & $\begin{array}{c}\text { Not } \\
\text { Applicable }\end{array}$ & Mean \\
\hline Quiet or solitude & 1 & 2 & 3 & 4 & 5 & 6 & \\
\hline Lack of human influence & $<1 \%$ & $3.8 \%$ & $12.5 \%$ & $28.1 \%$ & $54.8 \%$ & $<1 \%$ & 4.34 \\
\hline Wilderness experience & $<1 \%$ & $7.5 \%$ & $21.0 \%$ & $36.9 \%$ & $32.8 \%$ & $1.0 \%$ & 3.94 \\
\hline Environmental conditions & $<1 \%$ & $1.9 \%$ & $10.6 \%$ & $30.2 \%$ & $56.5 \%$ & $<1 \%$ & 4.42 \\
\hline
\end{tabular}

4. How did the number of people you saw during your visit to this wilderness compare with what you expected to see?

$\underline{11.9 \%} \mathrm{~A}$ lot less than you expected

$15.9 \%$ A little less than you expected

$\underline{45.5 \%}$ About what you expected
$14.8 \%$ A little more than you expected

7.8\% A lot more than you expected

4.1\% You didn't have any expectations

5. How crowded did you feel during your visit to this wilderness? [Circle ONE number only] Mean $=2.25$

\begin{tabular}{|l|c|c|c|c|c|c|c|c|c|}
\hline & \multicolumn{2}{|c|}{ Not at all crowded } & \multicolumn{2}{c|}{ Slightly crowded } & \multicolumn{2}{c|}{$\begin{array}{c}\text { Moderately } \\
\text { crowded }\end{array}$} & \multicolumn{2}{c|}{$\begin{array}{c}\text { Extremely } \\
\text { crowded }\end{array}$} \\
\cline { 2 - 10 } & 1 & 2 & 3 & 4 & 5 & 6 & 7 & 8 & 9 \\
\hline $\begin{array}{l}\text { Feelings } \\
\text { of } \\
\text { crowding }\end{array}$ & $42.2 \%$ & $25.3 \%$ & $14.5 \%$ & $8.2 \%$ & $4.9 \%$ & $3.1 \%$ & $1.3 \%$ & $<1 \%$ & $<1 \%$ \\
\hline
\end{tabular}

6. While you were in this wilderness today, about what percent of the time were you in sight of other groups? [Circle ONE number only] Mean $=16.5 \%$

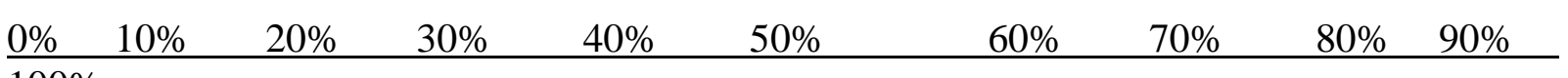
$\underline{100 \%}$

7. How many times did you see other groups while you were recreating today? If you saw the same group more than once, count each time separately.

Mean $=5.13$ times

8. With which size group would you rather visit this wilderness?

$\underline{81.9 \%}$ small (5 people or less)

$\underline{12.6 \%}$ medium (6-15 people) $\leq 1.0 \%$ large (16-25 people)

4.5\% makes no difference to me 
9. While recreating in this wilderness it would be O.K. so see other groups...
Mean 5.61 times
$\underline{57.2 \%}$ Doesn't matter
$\underline{42.8 \%}$ Does matter

10. What would be an acceptable percentage of time to see other groups while you are in this wilderness? [Circle ONE number only] Mean $=22.0 \%$

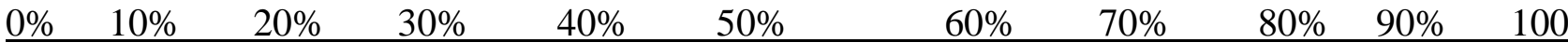

11. During your trip, did you have any conflicts with other parties? $2.1 \%$ Yes $\underline{97.9 \%}$ No

11a. If yes, briefly describe who was involved and the nature of the conflict. See Appendix

12. Is your trip today...

$\underline{50.7 \%}$ An overnight visit to this wilderness: if so, please list the total number of days you will stay.

Mean $=2.28$ days

$\underline{49.3 \%}$ A day trip to this wilderness: if so, please list the total number of hours you will stay today.

Mean=4.64 hours

\begin{tabular}{|c|c|c|}
\hline \multicolumn{2}{|c|}{$\begin{array}{l}\text { 13. In what activities on this list did you } \\
\text { participate during your visit to this wilderness? } \\
\text { [Please select all that apply.] }\end{array}$} & $\begin{array}{l}\text { 14. Which of those is your primary activity } \\
\text { for this recreation visit to this wilderness? } \\
\text { [Please select only ONE.] }\end{array}$ \\
\hline $\begin{array}{l}\text { Question } \\
25 \\
\text { Answers }\end{array}$ & (For questions $25 \mathrm{a}-25 \mathrm{o} ; 1=$ yes, $2=$ no) & $\begin{array}{c}\text { Question } 26 \\
\text { Answers(q26) }\end{array}$ \\
\hline $80.7 \%$ & Backpacking, camping & $31.3 \%$ \\
\hline $91.1 \%$ & $\begin{array}{l}\text { Viewing natural features such as scenery, wildlife, birds, flowers, } \\
\text { fish, etc. }\end{array}$ & $7.2 \%$ \\
\hline $22.4 \%$ & Visiting historic and prehistoric sites/areas (circle all that apply) & $<1.0 \%$ \\
\hline $42.9 \%$ & Nature study & $<1.0 \%$ \\
\hline $76.1 \%$ & General/other - relaxing, hanging out, escaping heat, noise, etc. & $4.1 \%$ \\
\hline $42.3 \%$ & Fishing - all types & $4.3 \%$ \\
\hline $12.6 \%$ & Hunting - all types & $3.2 \%$ \\
\hline $91.9 \%$ & Hiking or walking & $39.9 \%$ \\
\hline $9.7 \%$ & $\begin{array}{l}\text { Nonmotorized water travel (kayaking, rafting, canoe, etc.) (circle } \\
\text { one) }\end{array}$ & $<1.0 \%$ \\
\hline $42.1 \%$ & Other nonmotorized activities (swimming, games, sports) & $1.2 \%$ \\
\hline $27.8 \%$ & Gathering mushrooms, berries, firewood, or other natural products & $<1.0 \%$ \\
\hline $29.7 \%$ & Climbing & $2.0 \%$ \\
\hline $22.8 \%$ & Other (please specify) & $5.3 \%$ \\
\hline
\end{tabular}


15. Here is a list of possible reasons why people recreate at this wilderness. Please tell me how important each item is to you as a reason for recreating here.

\begin{tabular}{|l|c|c|c|c|c|c|}
\hline REASON & $\begin{array}{c}\text { Not at all } \\
\text { Important }\end{array}$ & $\begin{array}{c}\text { Somewhat } \\
\text { Important }\end{array}$ & $\begin{array}{c}\text { Moderately } \\
\text { Important }\end{array}$ & $\begin{array}{c}\text { Very } \\
\text { Important }\end{array}$ & $\begin{array}{c}\text { Extremely } \\
\text { Important }\end{array}$ & Mean \\
\hline & 1 & 2 & 3 & 4 & 5 & \\
\hline To be outdoors & $<1 \%$ & $<1 \%$ & $1.8 \%$ & $20.9 \%$ & $76.9 \%$ & 4.74 \\
\hline For relaxation & $<1 \%$ & $1.4 \%$ & $8.1 \%$ & $28.2 \%$ & $61.6 \%$ & 4.48 \\
\hline $\begin{array}{l}\text { To get away from the } \\
\text { regular routine }\end{array}$ & $<1 \%$ & $1.0 \%$ & $6.0 \%$ & $25.1 \%$ & $67.2 \%$ & 4.57 \\
\hline $\begin{array}{l}\text { For the challenge or } \\
\text { sport }\end{array}$ & $3.5 \%$ & $5.9 \%$ & $20.0 \%$ & $26.5 \%$ & $44.0 \%$ & 4.02 \\
\hline For family recreation & $13.0 \%$ & $8.0 \%$ & $15.5 \%$ & $23.6 \%$ & $39.9 \%$ & 3.70 \\
\hline For physical exercise & $1.9 \%$ & $3.3 \%$ & $13.0 \%$ & $29.8 \%$ & $52.1 \%$ & 4.27 \\
\hline To be with my friends & $6.0 \%$ & $5.0 \%$ & $13.4 \%$ & $25.2 \%$ & $50.4 \%$ & 4.09 \\
\hline $\begin{array}{l}\text { To experience natural } \\
\text { surroundings }\end{array}$ & $<1 \%$ & $<1 \%$ & $2.8 \%$ & $19.7 \%$ & $77.1 \%$ & 4.73 \\
\hline To develop my skills & $9.2 \%$ & $13.5 \%$ & $24.1 \%$ & $19.7 \%$ & $33.5 \%$ & 3.55 \\
\hline
\end{tabular}

16. Which of the following is the MOST important reason for this visit to this wilderness? [Select only ONE]

$\underline{38.5 \%}$ I went there because I enjoy the place itself

$\underline{38.4 \%}$ I went there because it's a good place to do the outdoor activities I enjoy

$\underline{17.7 \%}$ I went there because I wanted to spend more time with my companions

$5.4 \%$ I went there because it was close to home

17. What is your home ZIP code? OPEN OR $\underline{1.4 \%}$ Visitor is from another country

18. What is your age?

$\underline{4.9 \%} 16-20 \underline{13.5 \%} 21-30 \underline{14.2 \%} 31-40 \underline{19.5 \%} 41-50 \underline{23.0 \%}$ 51-60 $\underline{18.0 \%} 61-70 \underline{6.8 \%}$ over 70

19. What is your gender? $\underline{66.9 \%}$ Male $\underline{33.1 \%}$ Female

20. How many people are in your group today?

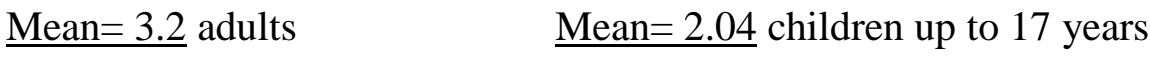

21. How many vehicles are in your group today?

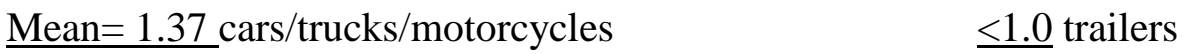


22. What is your highest level of education?

$14.2 \%$ High school or less $\underline{16.8 \%}$ Technical school/ 2 year college

$\underline{36.9 \%}$ Bachelor's degree $\underline{22.8 \%}$ Master's Degree

9.3\%Ph.D./Professional degree

23. Annual household income?

$\underline{12.9 \%} \$ 25 \mathrm{k}$ or less $\quad \underline{18.3 \%} \$ 25 \mathrm{k}-\mathrm{5}-5 \mathrm{k} \quad \underline{34.6 \%} \$ 50 \mathrm{k}-100 \mathrm{k}$

$\underline{20.0 \%} 100 \mathrm{k}-150 \mathrm{k} \quad \underline{7.8 \%} 150 \mathrm{k}-200 \mathrm{k} \quad \underline{6.4 \%} \$ 200 \mathrm{k}$ or over

24. Are you Hispanic, Latino, or Spanish origin? (please chose one) (q40)

$\underline{94.8 \%}$ No, not of Hispanic, Latino, or Spanish origin

$\underline{5.2 \%}$ Yes, of Hispanic, Latino, or Spanish origin

25 . With which racial group(s) do you closely identify? (please choose one or more)

98.6\% White $\quad \underline{2.9 \%}$ Black or African American $\quad \underline{6.6 \%}$ American Indian or Alaska Native

$\leq 1.0 \%$ Asian Indian $\quad 2.1 \%$ Japanese

$<1.0 \%$ Native Hawaiian $\quad 3.9 \%$ Chinese

$\leq 1.0 \%$ Korean $\quad \underline{2.0 \%}$ Filipino

$\underline{1.1 \%}$ Vietnamese $\quad \leq 1.0 \%$ Samoan

$\underline{2.4 \%}$ Other Asian or Pacific Islander 